\title{
A Novel Approach of Improving Battery Performance and Longevity of the Developed Electrically Assisted Triwheeler Vehicle by Implementing Torque Sensor Technology
}

\author{
Md. Jaber Al Rashid, ${ }^{1}$ Ataur Rahman, ${ }^{1}$ \\ Abu Raihan Mohammad Siddique, ${ }^{2}$ and A. K. M. Abdul Malek Azad ${ }^{2}$ \\ ${ }^{1}$ CARC, BRAC University, Dhaka, Bangladesh \\ ${ }^{2}$ EEE Department, BRAC University, Dhaka, Bangladesh \\ Correspondence should be addressed to Abu Raihan Mohammad Siddique; raihansiddique48@gmail.com
}

Received 28 February 2017; Accepted 4 May 2017; Published 17 July 2017

Academic Editor: Shankar Subramanian

Copyright ( $) 2017$ Md. Jaber Al Rashid et al. This is an open access article distributed under the Creative Commons Attribution License, which permits unrestricted use, distribution, and reproduction in any medium, provided the original work is properly cited.

\begin{abstract}
This paper presents a new approach to improving the battery performance and its longevity by the implementation of torque sensor pedal technology on the developed electric triwheeler vehicle (i.e., wheelchair). The paper has also discussed integration of the torque sensor technology with the overall electrical system of the vehicle. Incorporating the components of torque sensor technology reduces the human effort immensely by providing assistance from the battery bank to drive a hub motor while maneuvering the wheelchair using the torque sensor pedal. Field tests were carried out in three different stages, one with pedal, one with the throttle only, and with varying the load on the wheelchair, to distinguish the effect of load test on battery performance using the pedal. Results of the field tests reveal that the state of charge of batteries has been minimized using the pedal due to the contribution of the muscular energy of the user along with the battery energy to meet the total energy demand of the motor. Analyzing test results with the torque sensor pedal clarifies that the vehicle covers a longer distance, lessens power dissipation from the batteries, and reduces energy consumption from the batteries, which leads to improvement of the battery performance and its longevity ensuring sustainability of the electric vehicle.
\end{abstract}

\section{Introduction}

Millions of people are leading their daily lives with various types of disability. According to the World Health Organization report, statistical data stated that almost $10-20 \%$ of the total world's population have lived with disability [1]. Among the total number of disabled people around the globe, nearly $80 \%$ live in developing countries [2] and an estimated $15-20 \%$ of the poorest people are physically impaired [3]. These physically handicapped people are among the world's largest minority because of being neglected in the society and isolated from all types of mainstream development initiatives and social services such as health, education, housing, and jobs [2]. Due to the lack of opportunities for the disabled people (e.g., paralyzed people) to move independently and the lack of convenient assistive modes of transport, qualified people with disability experience greater unemployment and even have lower income than those without any disability [4]. Moreover, the lack of suitable and comfortable mobility devices for disabled children (such as orthotic devices, strollers, and walkers) also hinders their choice of going to school for study [5].

For some developing and economically poorer countries, a large proportion of disabled people completely rely on crutches, manually driven wheelchairs, and other cheaper assistive devices for their indoor and outdoor mobility. Even though these four-wheeler manual wheelchairs assist disabled people in their daily lives for their movements greatly, there is no overlooking of the substantial amount of physical force that needs to be exerted by the physically handicapped people with their bare hands to turn the wheels of the manual wheelchairs [6]. One of the drawbacks of using the 
manually driven wheelchair is that the occupant experiences severe pain and repetitive strain injury (RSI) of the upper extremities, and even prolonged usage of manually driven wheelchairs causes shoulder pain leading to musculoskeletal injury [7]. Thus, the use of cost-effective battery operated wheelchairs for both indoor and outdoor movement is very essential to improve the lifestyles of disabled people.

Over the years, the technological advancement has made significant progress to build up electric wheelchairs for helping physically challenged people to lead a normal life, allowing them to move freely [8]. Conventional electric wheelchairs which are available for the disabled people are entirely driven by motors and a set of batteries are used to meet the total power requirement for the motors so that all wheels are moving and turning smoothly at a faster speed to provide a comfortable experience [9]. Electrically driven wheelchairs minimize the stress induced on the wheelchair users ensuring both indoor and outdoor mobility for longer distances over a longer period of time [8]. Motorized tricycles use fuel that is expensive, whereas electric tricycles are powered by batteries only and thus do not cause any pollution to the environment [10].

Electrification of vehicles such as rickshaws, cars, electric tricycles, and four-wheeler electric wheelchairs ensures zero contribution of pollution to the environment unlike any combustion engine $[11,12]$. Different types of electric vehicles such as hybrid electric vehicles (HEVs) $[13,14]$ and plug-in electric vehicles (PEVs) [15] also produce little emission of pollutants due to their energy saving ability [16]. Different ways of battery power management are evident in different types of electric vehicles. The battery electric vehicle (BEV) can be used on the roads until the battery is discharged and PEV batteries can be charged by taking power from the electric supply of the house [16]. Even though plug-in hybrid vehicles (PHEVs) can be operated in full-electric mode and offer improved energy efficiency without deteriorating performance, $\mathrm{PHEV}$ s pose challenges to find a solution regarding power management optimization [17]. Numerous works were performed on optimum power management of hybrid electric vehicles. Several energy management strategies of PHEVs compared travel distance and preceding knowledge of the trip during the charge depletion process of all-electric-range operation modes [18]. The result obtained from this study showed that the all-electric-range operation method provides all the advantages of a fully electric vehicle, but expensive batteries and an electric motor of higher rating would be needed. Battery operated electric vehicles such as rickshaws are usually driven by a throttle system resulting in complete elimination of human effort and in turn causing higher energy consumption from batteries only [19]. Therefore, the national grid gets overloaded due to the utilization of battery energy more quickly and regularly.

Electric tricycles rely entirely upon batteries to supply power to the motor. The power supplied by batteries to the load can only be plentiful to run the electric tricycle for about an hour. Hence, the user needs to pedal the cycle with lots of muscular energy because of the heavy weight of the tricycle to reach the destination or the need to recharge the batteries to compensate for the rapid power usage by batteries [10].
Optimum power management of the batteries that are used in traditional electric wheelchairs has remained a challenge that needs to be dealt with to ensure improvement in battery performance of batteries and increase battery longevity.

This paper focuses on how sealed lead-acid batteries' performance and power management can be improved by implementing the torque sensor technology on the designed and developed triwheeler electric wheelchair. This paper has been categorized into five sections. Section 1 gives a brief overview of the electric wheelchair and its importance among the disabled people compared to that of manually driven wheelchairs. The mechanical design and construction of the electric wheelchair is discussed in Section 2. Section 3 highlights the implementation of the torque sensor technology on the developed electric wheelchair and the design of the overall electrical system. Section 4 provides results and analysis of the battery performance due to using the torque sensor pedal during the field tests. Section 5 provides a conclusion regarding the developed electric wheelchair along with the overall impact of incorporating the torque sensor pedal to improve the battery's longevity and performance.

\section{Mechanical Design and Development of the Electric Wheelchair}

Manually driven wheelchairs are lightweight, cheaper, and readily available around the world among disabled people. Even though electric wheelchairs are relatively more expensive and heavier in weight than manual wheelchairs, these motor-driven wheelchairs bring about immense benefit to wheelchair users in terms of convenience and suitability for both indoor and outdoor movement without being dependent on others. The three-wheeler electrically assisted wheelchair has been designed with precision and accuracy using the "PSpice schematic design manager" software. Figure 1 shows a side view and front view design of the electric wheelchair with dimensions and Figure 2 displays the back view and top view design.

While designing the electric wheelchair, several factors were considered to ensure that the developed electric wheelchair can be driven with comfort and the design meets the suitability for physically handicapped people (e.g., paralyzed patients). Stability of the developed electric wheelchair, reliability, safety while driving the wheelchair, comfort, and suitability for the wheelchair users were taken into consideration while determining different dimensions of the designed electric wheelchair. Table 1 provides the dimensions details for different mechanical parts of the electric wheelchair shown in Figure 1. Table 2 provides a total overview of all the required electric and mechanical components used for the wheelchair design.

The whole body frame of the electric wheelchair was built up of tubular steel by following the accurate measurements of length, width, and height of the electric wheelchair design. The process of constructing the wheelchair involved cutting of the raw materials precisely and accurately, welding steel sheets with precision to ensure the frame of the seat of the wheelchair is strong enough to hold the weight of the 


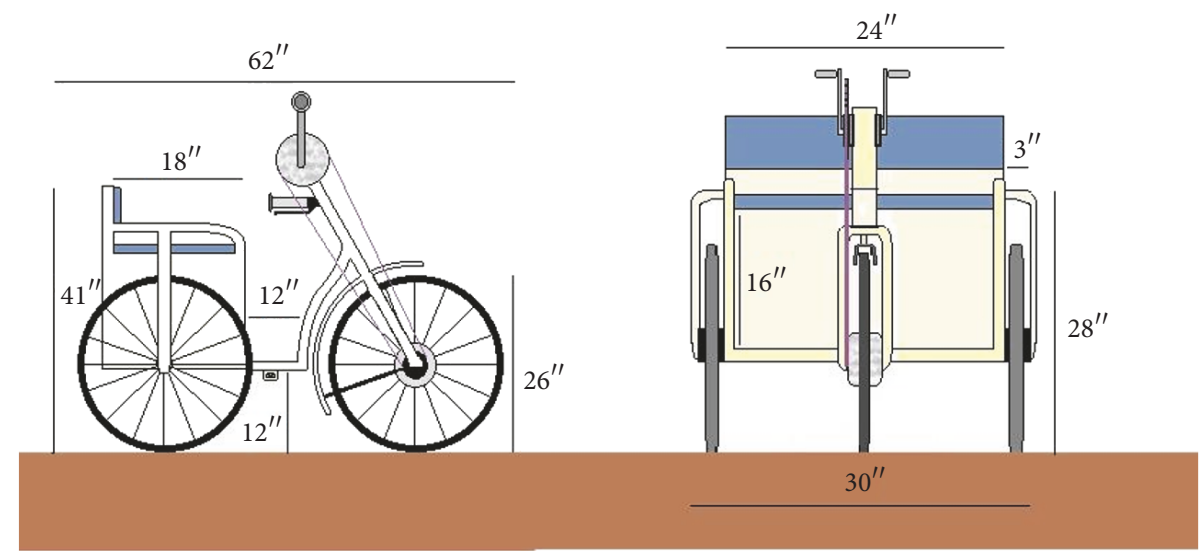

Figure 1: Side view and front view design.
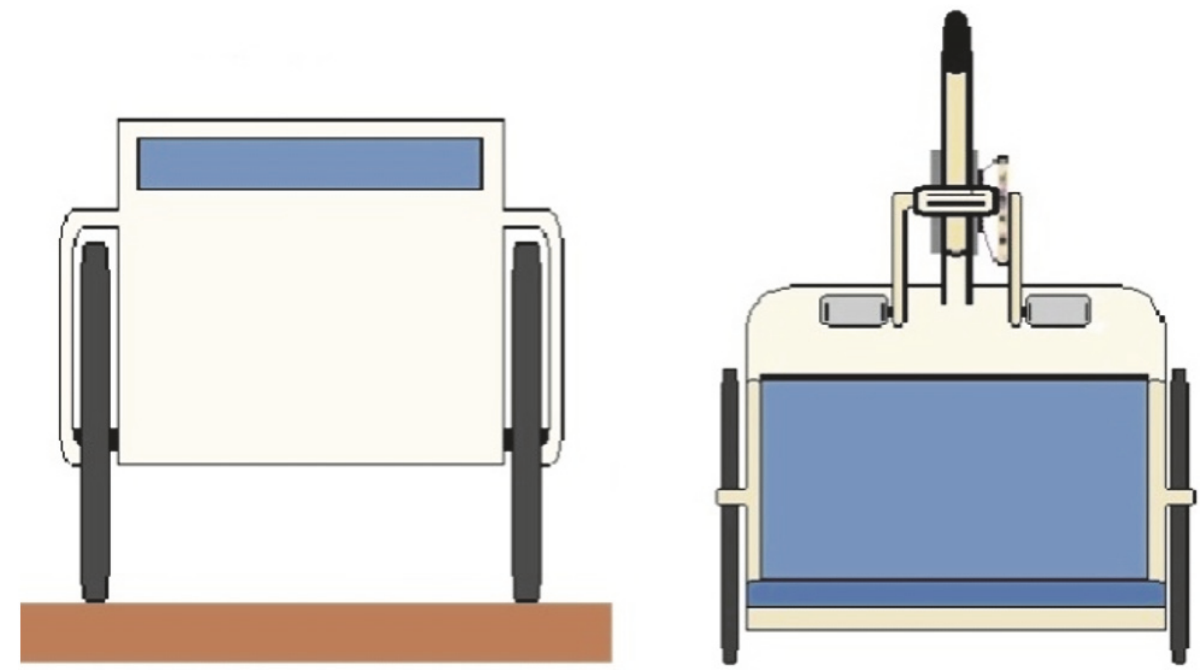

Figure 2: Back view and top view design.

TABLE 1: Dimensions details of the electric wheelchair.

\begin{tabular}{lc}
\hline Category & Length \\
\hline Length of the electric wheelchair & 62 inches \\
Width of the electric wheelchair & 30 inches \\
Height of the wheelchair & 41 inches \\
Width of the chair only & 18 inches \\
Length of the chair only & 24 inches \\
Height of the seat from the ground & 28 inches \\
Diameter of thicker wheels & 26 inches \\
Length of the footrest & 12 inches \\
\hline
\end{tabular}

occupant, and grinding to complete the mechanical design. The construction procedure to produce the final developed electric wheelchair is shown in Figure 3. After completion of the electric wheelchair, the torque sensor pedal was installed in the upper portion of the head tube above the handlebar of the electric wheelchair. A spindle has been used to hold the pedal while assembling the torque sensor pedal and a lock pin is used at the back of the pedal to stabilize the measuring circuitry while turning the chain-wheel crack so that the torque can be measured by the sensor module and to ensure wires connecting the sensor with the pedal do not come out from the pedal. Three sealed lead-acid batteries were placed at the bottom of the seat along with the torque adjuster circuit. Figure 4 shows the mechanical assembly of the torque sensor pedal with the sensor module. The wheelchair is equipped with the throttle, torque sensor pedal, brake at the front wheel, motor $(250 \mathrm{~W}, 36 \mathrm{~V})$, three sealed lead-acid batteries (each of them $12 \mathrm{~V}, 12$ Ah connected in series), $36 \mathrm{~V}$ charge controller with LCD, a traditional front brake, and a horn. Figure 5 presents the final completed electric wheelchair based on the design shown in Figures 1 and 2.

\section{Design and Implementation of the Electrical System}

After the completion of the mechanical design of the electric wheelchair, various electrical components were integrated together on the developed electrically assisted wheelchair. The developed three-wheeler electrically assisted wheelchair 
TABLE 2: Overview of electric and mechanical components of the electric wheelchair with specifications.

\begin{tabular}{|c|c|c|}
\hline Component category & Type of component & Specifications \\
\hline Sealed lead-acid batteries & Electric & $\begin{array}{c}3 \text { batteries (each } 12 \mathrm{~V}, 12 \mathrm{Ah}) \\
\text { connected in series }\end{array}$ \\
\hline $\begin{array}{l}\text { Hub motor with motor } \\
\text { controller }\end{array}$ & Electric & $\begin{array}{c}36 \mathrm{~V}, 250 \mathrm{~W}, 300 \mathrm{rpm} \text {; maximum } \\
\text { current flow is } 17 \mathrm{~A} \text { and low-voltage } \\
\text { protection is } 31.5 \mathrm{~V} \text { for the motor } \\
\text { controller }\end{array}$ \\
\hline Torque sensor module & Electric & $\begin{array}{c}\text { Output torque }>15 \mathrm{Nm} \text {, output, } \\
\text { linear, zero start, } 0.5 \sim 4.5 \mathrm{~V}, V_{\mathrm{cc}}= \\
5.15 \mathrm{~V}(+/ 0.15 \mathrm{~V})\end{array}$ \\
\hline Torque adjuster circuit & Electric & $\begin{array}{c}\text { Consists of a voltage regulator } \\
\text { (LM7805), op-amp (LM358), } \\
\text { potentiometer (10 k), resistors } \\
\text { (5 kiloohms, } 10 \text { kiloohms), } \\
\text { capacitors }(0.1 \mu \mathrm{F}), \text { power supply } \\
\text { connectors }\end{array}$ \\
\hline $\begin{array}{l}\text { Charge controller with } \\
\text { Low-Voltage Disconnect } \\
\text { (LVD) }\end{array}$ & Electric & $36 \mathrm{~V}, 25 \mathrm{~A}, \mathrm{LVD}$ at $36.2 \mathrm{~V}$ \\
\hline Throttle & Electric & $\begin{array}{c}\text { Biasing voltage is } 5 \mathrm{~V} \text {; operating } \\
\text { range } 0.8-4.5 \mathrm{~V} \text { (acting as a } \\
\text { potentiometer) }\end{array}$ \\
\hline Horn and front light & Electric & $\begin{array}{l}\text { Works at } 12 \mathrm{~V} \text { from the battery } \\
\text { supply }\end{array}$ \\
\hline $\begin{array}{l}\text { Body frame and the front } \\
\text { handlebar }\end{array}$ & Mechanical & Customized steel tubed frame \\
\hline Torque sensor pedal & Mechanical & $\begin{array}{l}\text { Aluminum frame for crank shaft; } \\
\text { the number of gear teeth is } 48\end{array}$ \\
\hline $\begin{array}{l}\text { Wheel type and dimension } \\
\text { of the wheel (including tire } \\
\text { size) }\end{array}$ & Mechanical & $\begin{array}{l}\text { Larger and narrow, with the } \\
\text { dimension of the front wheel and } \\
\text { each rear wheel being } 26 \text { inches and } \\
26 \text { inches, respectively }\end{array}$ \\
\hline $\begin{array}{l}\text { Wheels with dimension } \\
\text { (excluding the tire size) }\end{array}$ & Mechanical & $\begin{array}{l}\text { Front wheel size is } 24 \text { inches and } \\
\text { rear wheel size is } 24 \text { inches }\end{array}$ \\
\hline Front brake & Mechanical & Traditional V-brake \\
\hline Chain and a small sprocket & Mechanical & $\begin{array}{l}\text { Chain and sprocket are cast iron } \\
\text { material; the sprocket has } 24 \text { teeth }\end{array}$ \\
\hline Front mudguard & Mechanical & Steel body \\
\hline
\end{tabular}
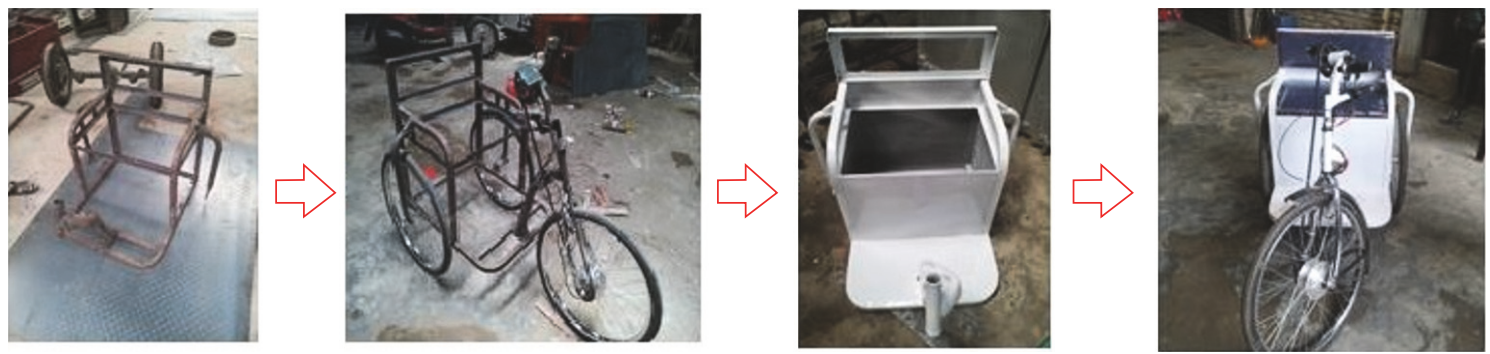

FIGURE 3: Construction procedures of the electric wheelchair.

consists of a $250 \mathrm{~W}$ hub motor attached at the front wheel, a $36 \mathrm{~V}$ motor controller, a $36 \mathrm{~V}$ charge controller with LowVoltage Disconnect (LVD), and three $12 \mathrm{~V}, 12 \mathrm{Ah}$ sealed lead-acid batteries connected in series which provide a total of minimum $36 \mathrm{~V}$. Three rechargeable sealed lead-acid batteries as shown in Figure 6 are connected in series and placed together below the seat compartment of the electric wheelchair. For electric vehicle conversion, sealed lead-acid batteries are a suitable and feasible battery technology on the market. A sealed lead-acid battery is an electrochemical 


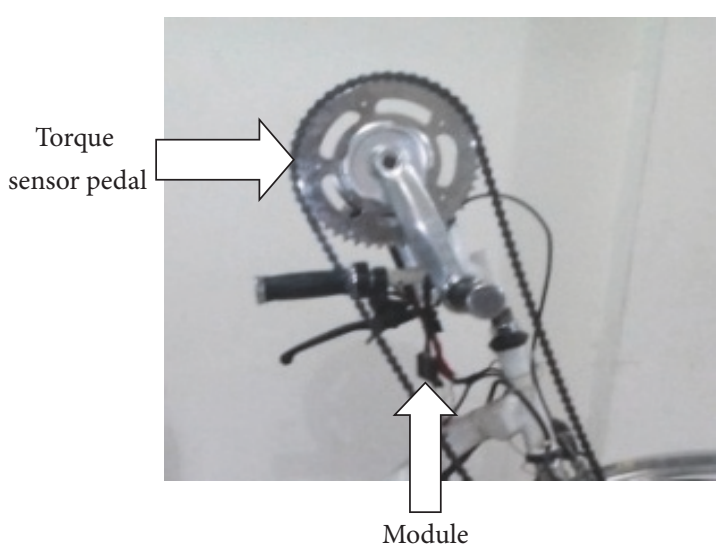

FIGURE 4: Mechanical assembly of the torque sensor pedal.

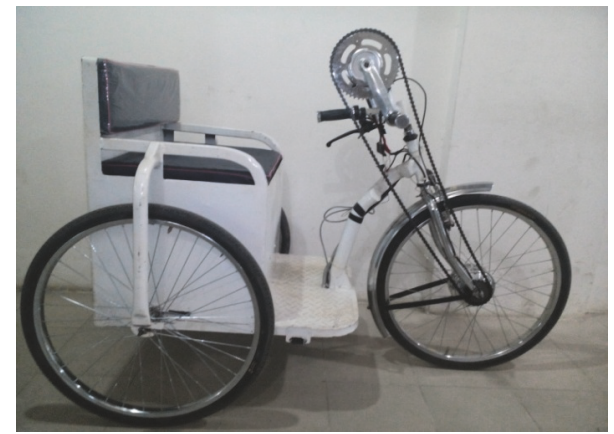

FIGURE 5: The developed electrically assisted wheelchair incorporated with a torque sensor pedal.

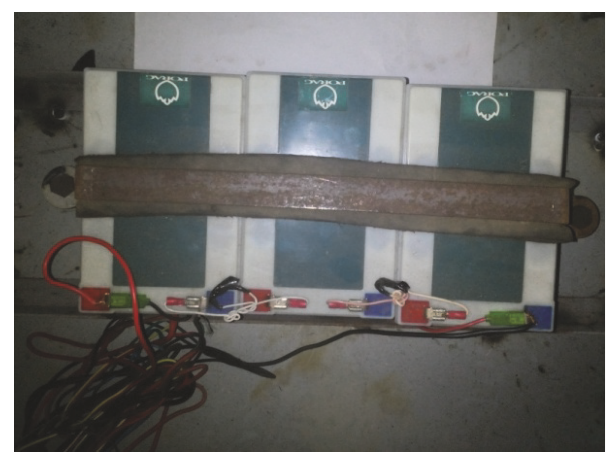

FIgURE 6: Sealed lead-acid batteries connected in series.

cell that converts chemical energy into electrical energy due to spontaneous chemical reactions [10]. Figure 7 presents a $36 \mathrm{~V}, 250 \mathrm{~W}$ hub motor mounted on the front wheel of the wheelchair which is lightweight with a longer lifespan and requires little maintenance [10]. Moreover, one of the major features of the produced electric wheelchair is introducing the torque sensor pedal along with the torque sensor module and the torque adjuster circuit.

The block diagram of the complete electrical system design is shown in Figure 8, which enables the battery bank

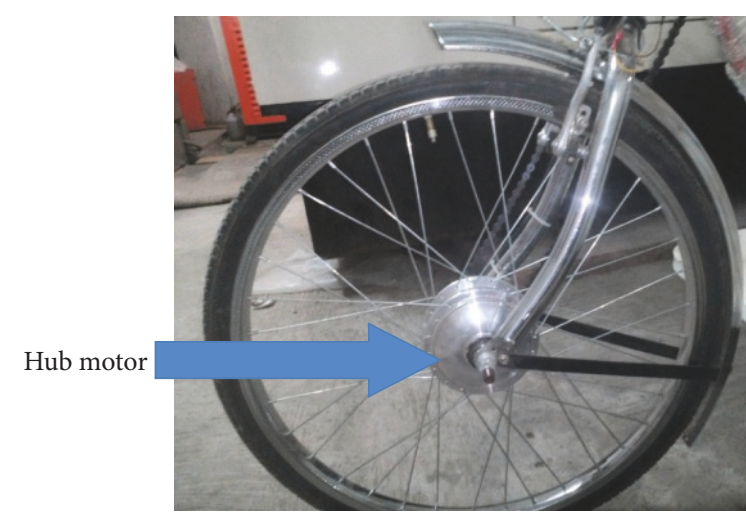

FIgURE 7: A $250 \mathrm{~W}$ hub motor attached to the front wheel.

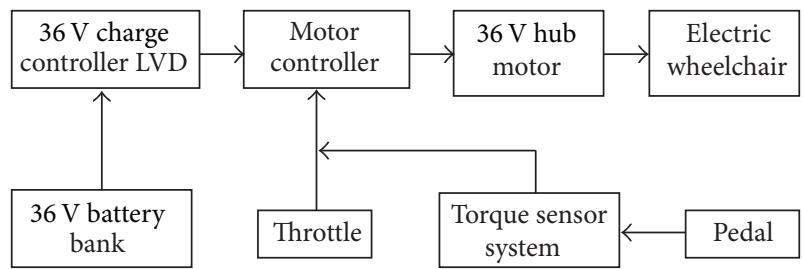

FIGURE 8: Block diagram of the overall electrical system design.

to provide the required power to the $36 \mathrm{~V}, 250 \mathrm{~W}$ hub motor using both the throttle and the torque sensor pedal individually in order to drive the electric wheelchair. The motor controller is used to control the speed of the hub motor while operating the wheelchair using the throttle and the torque sensor pedal. According to Figure 8, a $36 \mathrm{~V}, 25 \mathrm{~A}$ charge controller is connected to the battery and also connected with the motor controller to disconnect the motor from the $36 \mathrm{~V}$ battery bank when fully charged batteries (100\% SOC) get discharged till 50\% SOC. The purpose of disconnecting the load from the battery is to minimize the overuse of the batteries by preventing batteries from being discharged below $50 \%$ SOC $(36.3 \mathrm{~V})$. The objective of incorporating the torque sensor pedal with the torque adjuster circuit is to allow the wheelchair user to receive electrical assistance from the hub motor equipped with $36 \mathrm{~V}$ battery bank to ease up the pedaling efforts significantly.

3.1. Integrating the Torque Sensor Module with the Pedal on the Developed Electric Wheelchair. The torque sensor pedal with the module integrated with the electric wheelchair was designed and developed by Suzhou Victory Sincerity Technology Co., Ltd. [20]. This Chinese company usually develops and designs these torque intelligent sensor systems by maintaining the European Standard EN15194 and the Japanese Industrial Standards (JIS). The torque sensor or torque transducer equipped with the pedal and the module is a device that can be used for measuring the torque applied to a rotating system. One type of torque sensor is the rotary torque sensor that measures the dynamic torque applied when the torque sensor pedal rotates [21,22]. The torque sensor reads 


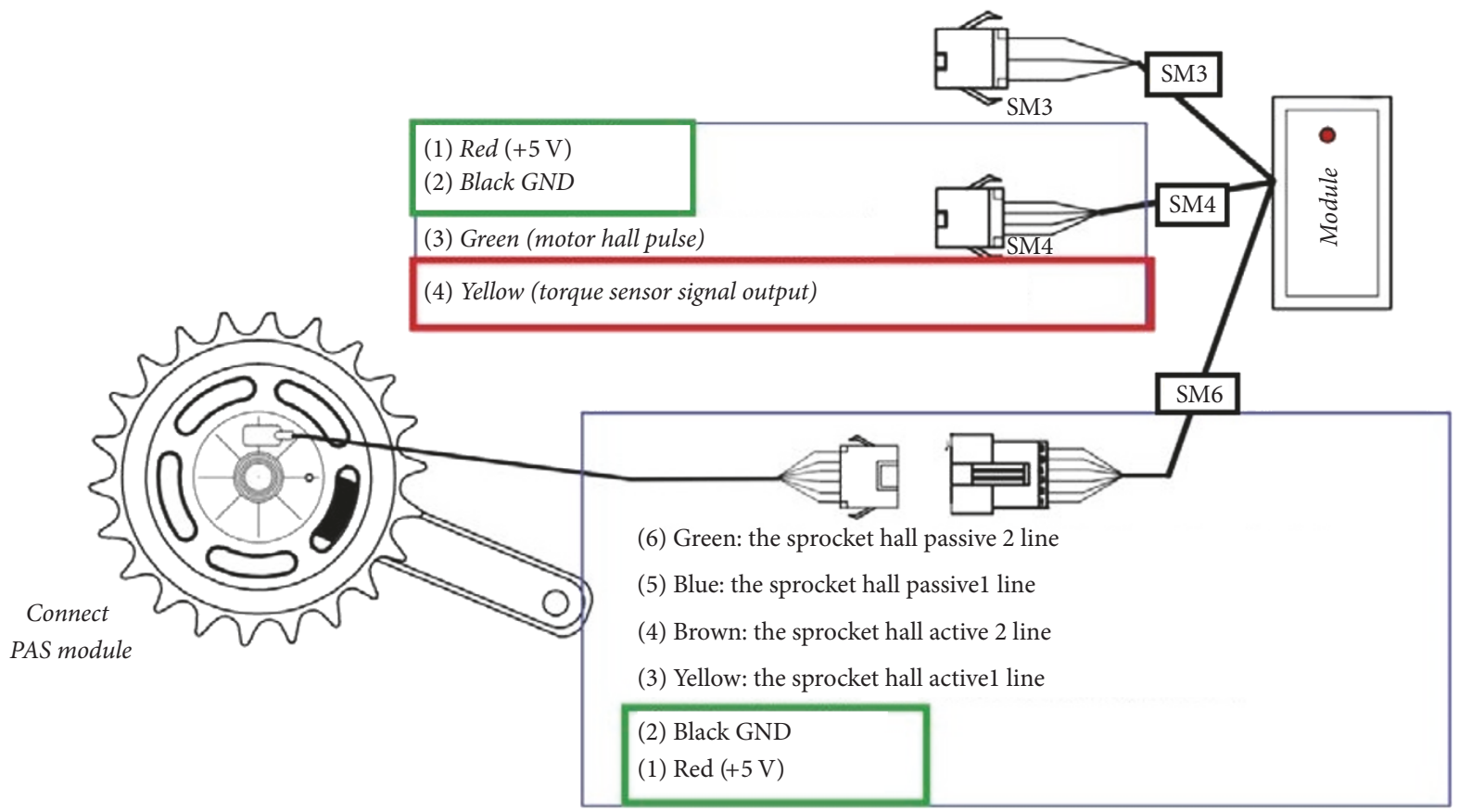

FIGURE 9: Electrical connection diagram for the operation of the torque sensor module.

the torque applied on the specified crank or shaft and converts it to the corresponding electrical output voltage. The output voltage has a linear relationship with the corresponding applied torque. The torque sensor pedal with the torque sensor module has got some useful features; for example, the sensor shows instant response when pressure on the sensor pedal is applied or when pedaling is stopped [23]. Technical parameters of the torque sensor and the specifications are available in [24]. The electrical connection diagram for the independent operation of the torque sensor module incorporated with the torque sensor pedal is extracted separately from the main circuit diagram available in [24] because a different controller is incorporated with the module and the torque sensor on the electric wheelchair. Figure 9 displays the extracted electrical connection diagram $[23,24]$ for the torque sensor module and the pedal. The diagram indicates that the input biasing voltages for the sensor are the red and black wires for SM6. The red wire from SM6 has to be supplied with a DC input voltage of $5 \mathrm{~V}$ and the black wire in SM6 for the module must be connected to the ground (marked as GND). The yellow wire in the SM4 for the module is labeled as the output voltage from the torque sensor which has to be used for the motor speed control. The yellow wire of the SM4 for the module gives the equivalent output voltage with respect to the ground depending on the applied torque in the pedal crank of the sensor. Hence, this is the output voltage that has been fed to the externally designed torque adjuster circuit to obtain the amplified output torque voltage that has to be provided to the motor controller for adjusting the speed of the motor and to assist the wheelchair user by allowing the motor to rotate at the time of pedaling.

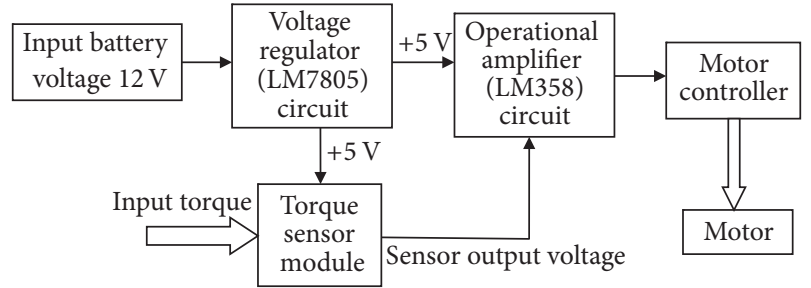

FIGURE 10: Block diagram of the torque adjuster circuit.

3.2. Design and Implementation of the Torque Sensor Adjuster Circuit. The torque sensor gain adjuster circuit has been designed and simulated using software known as "Proteus 7 Professional." The objective of designing and implementing the torque adjuster gain circuit is to obtain a high output voltage which can be fed to the motor controller to drive the motor at a relatively desired speed to reduce the manual effort during the time of rotating the torque sensor pedal. The block diagram of the designed external torque adjuster circuit is shown in Figure 10. A voltage regulator LM7805 is used in the circuit to obtain a $+5 \mathrm{~V}$ DC as the output voltage from the regulator when a minimum $12 \mathrm{~V}$ input voltage is provided from the battery. The fixed $+5 \mathrm{~V}$ is needed to turn on the sensor module as well as to bias the op-amp (LM358). The biasing of LM358 with a low voltage is performed for controlling and limiting the speed of the motor by limiting the output torque voltage of the amplifier to a maximum reasonable value without interrupting the whole system by motor switching or sudden stop runs [24]. The output voltage of the sensor goes to the noninverting input terminal of the 


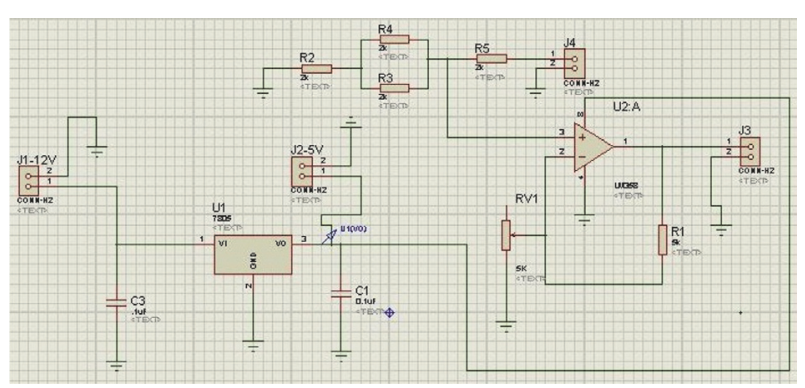

FIGURE 11: Design of the torque adjuster circuit.

IC known as LM358. The output voltage from the operational amplifier is fed to the terminals of the motor controller unit which is connected with the hub motor.

Figure 11 illustrates the circuit design with all the circuit components and their connections in the Proteus software. Two capacitors, each with a value of $0.1 \mu \mathrm{F}$, are used across the input and output terminals of the LM7805 regulator. The voltage regulator circuit in Figure 11 consists of 4 resistors $\left(R_{2}, R_{3}, R_{4}\right.$, and $\left.R_{5}\right)$ with the same value of $2 \mathrm{k}$ which are connected to the noninverting input terminal of LM358. A $5 \mathrm{k}$ feedback resistor $\left(R_{1}\right)$ is connected to the inverting input terminal of the op-amp via a $5 \mathrm{k}$ variable resistor known as a potentiometer. The circuit diagram also shows the connection of 4 connector blocks for the purpose of designing a Proteus Circuit Board (PCB) of this circuit using software known as "Areas." The hardware implementation of the torque adjuster circuit in the PCB is shown in Figure 12. While running the vehicle using the torque sensor pedal, the equivalent torque voltage generated by the force applied on the pedal may be very high (around 3-4 V). A potentiometer with maximum resistance $\left(R V_{1}\right)$ of $5 \mathrm{k}$ has been connected as shown in Figure 11 so that the gain of the amplifier can be varied. Since the amplified output voltage $\left(V_{1}\right)$ of the amplifier circuit has been fed to the controller unit of the motor, increasing the gain of the amplifier by rotating the knob of the potentiometer allows the output voltage to increase and vice versa. The gain of the noninverting amplifier can be found using (1), and the final output voltage $\left(V_{1}\right)$ fed to the motor controller after amplification is expressed in (2).

$$
\begin{aligned}
\text { Gain } & =1+\frac{R_{1}}{R V_{1}} \\
V_{1} & =\left(1+\frac{R_{1}}{R V_{1}}\right) \times V_{\text {in }} .
\end{aligned}
$$

Consequently, the speed of the motor can be controlled depending on the amplified output voltage. Instead of passing the output voltage from the torque sensor module into the noninverting input of LM358, the voltage regulator circuit has been designed to minimize the high output torque voltage $\left(V_{\text {out }}\right)$ from the torque sensor module up to $60 \%$ depending on the value of resistors used for designing the circuit. Therefore, the reduced voltage $\left(V_{\text {in }}\right)$ is fed to the input of the amplifier circuit and can be expressed by using (3), where $V_{\text {out }}$ is the voltage output from the torque sensor corresponding to the applied torque during rotating the torque sensor pedal.

$$
V_{\text {in }}=0.6 \times V_{\text {out }} \text {. }
$$

The circuit has been designed in such a way with a certain maximum gain so that the speed of the vehicle may not be too high. Thus, there is a minimum voltage which corresponds to the minimum applied torque required to start the motor as well as a cut-off voltage (maximum torque voltage) for limiting the speed of the motor [25]. If the output torque voltage is more than the cut-off voltage, the design is made such that the motor will keep on assisting the wheelchair user at its maximum preset level set by the user. This ensures the safety of the motor and the wheelchair user [26] and subsequently allows the user to control the maximum speed of the motor by varying the gain of the amplifier to the desired value.

\section{Field Tests}

The field test of the electrically assisted wheelchair was carried out beside the National Institute of Diseases of the Chest and Hospital area which is located at Mohakhali, Dhaka, Bangladesh. The outdoor test site was considered to be suitable for testing the wheelchair because of the minimum traffic congestion and roads with little potholes. The particular test site fulfilled the site selection criterion which includes the type of the road surface with minimum intervention of any kind from the surroundings.

The field test was operated at the premises of the Centre for Rehabilitation of the Paralyzed (CRP) for three different stages to distinguish the effect of implementing the torque sensor pedal technology on the performance and the longevity of the battery used to drive the wheelchair. Three different stages are included as follows:

(i) The use of throttle only, without taking assistance from the torque sensor.

(ii) Propelling the electric wheelchair by the use of the torque sensor pedal to determine the performance enhancement of the battery.

(iii) Increasing the load on the wheelchair to determine the changes in the battery performance while maneuvering the wheelchair using the torque sensor pedal.

The major focus of conducting the field test was to assess, evaluate, and analyze the impact of including the torque sensor pedal technology on the battery performance of the developed electric wheelchair. The purpose of the field test was to compare and contrast how the performance of the batteries used in the electric wheelchair varied in terms of the energy supplied by the battery using the torque sensor pedal as well as with the throttle (i.e., without the torque sensor pedal) while running the developed electric wheelchair. Moreover, the test run of the wheelchair was conducted both by using the torque sensor pedal and without the assistance of the torque sensor pedal to obtain the difference in the total distance covered by the wheelchair until the fully charged battery is discharged down to $50 \%$ SOC and to find out the 

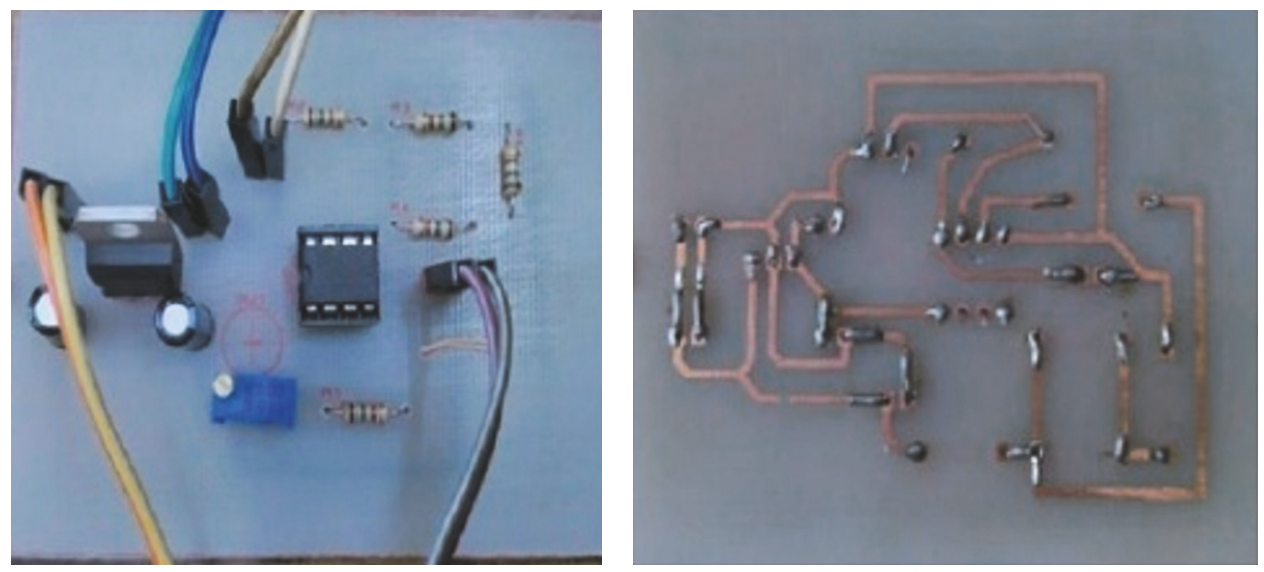

FIGURE 12: Hardware implementation of the PCB design.

power consumption by the load from the batteries in all three different stages of the field test.

4.1. Data Acquisition Technique. During the field test, highquality digital multimeters were used to measure the battery supply voltage and the torque sensor circuit input as well as the output voltage. Battery supply voltage readings were measured by connecting one multimeter in parallel across the $36 \mathrm{~V}$ battery used to provide power to the electric wheelchair. Two more multimeters were also connected in parallel across the two terminals of the torque sensor circuit to determine both input and output voltage readings of the torque sensor circuit. Current readings supplied by the battery to the load were measured at regular intervals of time by using a digital clamp meter. The digital clamp meter was connected in series with the battery and the motor by clamping it onto a wire. Throughout the different stages of the field test, GPS tracking Android software known as Endomondo was used to record the total distance travelled by the wheelchair.

All the parameters measured by multimeters and clamp meter were recorded by using a high-resolution digital single lens reflex (DSLR) camera throughout the whole runtime of the field tests. Later, all these recorded battery voltages and current readings drawn by the load from the batteries were retrieved from the high-resolution DSLR camera videos at 20 -second intervals for the analysis of the obtained data.

4.2. Results and Analysis of the Field Test without Torque Sensor Pedal. During the whole field test, real-time monitoring of the changes in battery voltage and current readings drawn by the load was achieved by the help of a highresolution DSLR camera. The battery supply profile as shown in Figure 13 includes the variations of battery voltage and current data drawn from the battery and collected at regular intervals of time. The graph plotted in Figure 13 shows that the average current supplied by the battery to the load is $5 \mathrm{~A}$ and the average battery supply voltage is $36.5 \mathrm{~V}$. From the graph, the maximum current drawn from the battery is 16.2 A when the total battery voltage is $33.6 \mathrm{~V}$ at 4380 seconds. The test was conducted with the use of throttle only (without

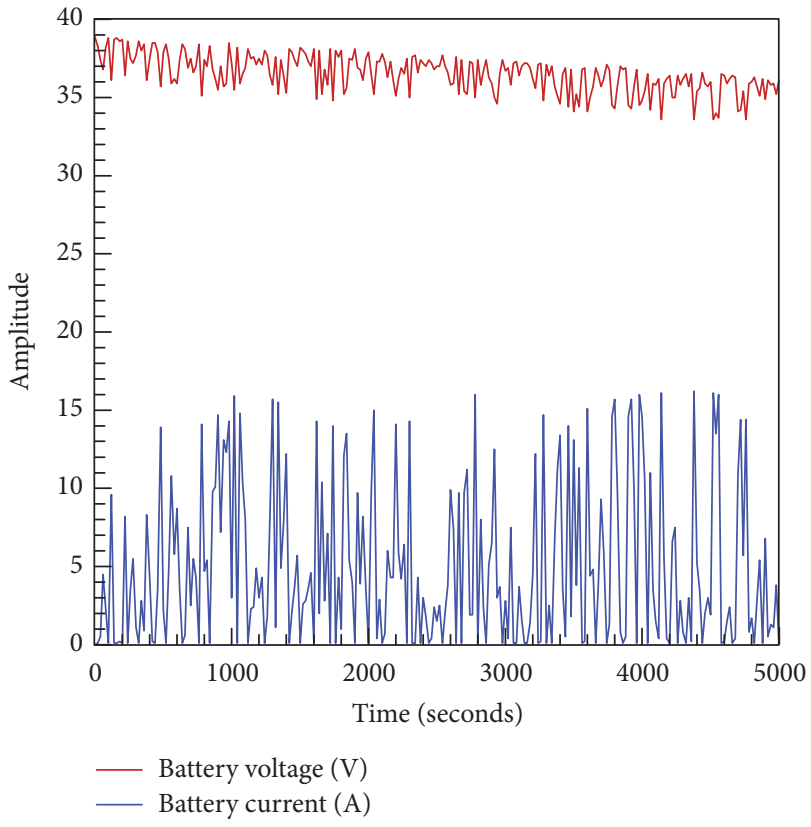

FIGURE 13: Battery performance without the operation of the torque sensor.

any assistance from the torque sensor pedal) until the battery voltage fell from $100 \%$ SOC to $50 \%$ SOC. The graph reveals that the maximum battery voltage is $38.9 \mathrm{~V}$ and the battery voltage drops to $36.3 \mathrm{~V}$ at the end of the field test.

The power $(P(t))$ dissipated from the battery is calculated by multiplying the recorded battery voltage $(V)$ readings with measured current $(I)$ readings at time $(t)$ drawn from the battery using (4) as mentioned below:

$$
P(t)=V(t) \times I(t),
$$

where $P(t)$ is the instantaneous power supplied by the battery at time $t, V(t)$ is the total voltage supplied by the battery at time $t$, and $I(t)$ is the total current drawn from the battery at time $t$. Since the $36 \mathrm{~V}$ hub motor has been connected directly 


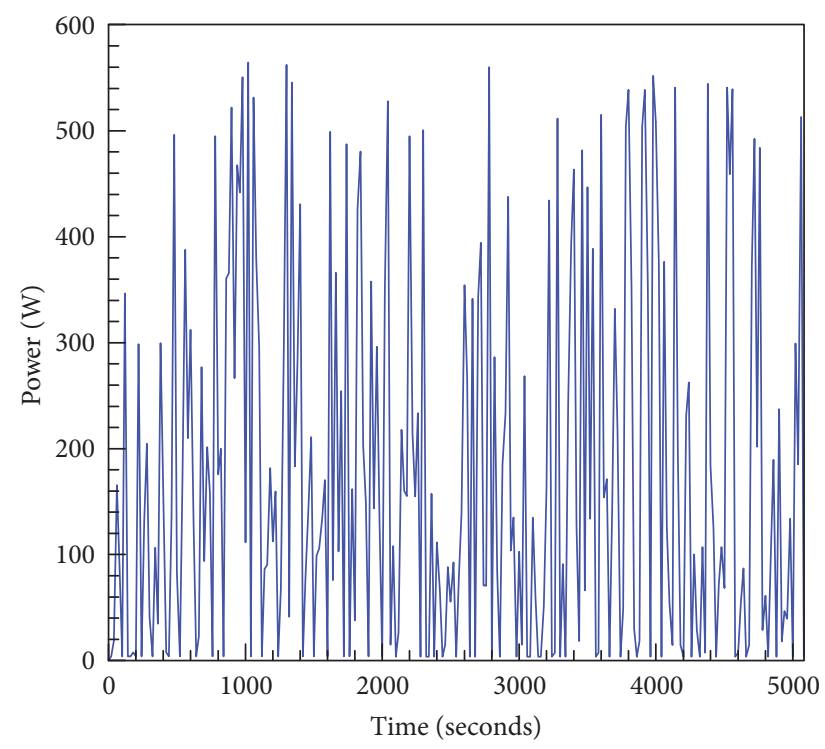

FIGURE 14: Power dissipation profile of the battery during the field test without the use of a torque sensor pedal.

across the $36 \mathrm{~V}$ battery, the load motor voltage is equivalent to the battery voltage. Similarly, while driving the wheelchair with the throttle only, the current drawn by the motor is equal to the battery supply current. Therefore, applying the same equation as mentioned above, the power consumed by the load is equal to the power supplied from the battery. Power supplied by the battery or the change in the power consumed by the load is presented in Figure 14. The graphical representation depicts that the average power drawn from the battery bank is $177.44 \mathrm{~W}$ and the maximum power consumed by the load from the battery is $564.45 \mathrm{~W}$, which is the same as the maximum power supplied by the battery. Energy $(E(t))$ supplied by the battery can be expressed using

$$
E(t)=P(t) \times t .
$$

The total area under the graph of battery power dissipated against time is calculated to obtain the total amount of energy supplied by the battery to the load which is equal to the total amount of energy consumed by the load from the battery. The formula for the trapezoid rule has been applied to calculate the area of each trapezium drawn under the curve of power dissipated versus time as shown in Figure 14. According to the trapezoid rule, the area of one trapezium $(A)$ is calculated by using the following equation:

$$
A=\frac{P\left(t_{i}\right)+P\left(t_{i}\right)}{2 \times\left(t_{i}-t_{j}\right)}
$$

where $P\left(t_{i}\right)$ is the amount of power supplied by the battery at time $\left(t_{i}\right), P\left(t_{j}\right)$ is the numerical power value obtained from the graph at $\left(t_{j}\right), i=0,1,2, \ldots, N-1, N, j=i+1$, and $\left(t_{i}-t_{j}\right)$ is the width of the trapezium. The graph in Figure 14 is drawn between $t_{0}=0 \mathrm{~s}$ and $t_{254}=5080 \mathrm{~s}$, and the total number of trapeziums that can be drawn within this time interval of uniform width is denoted by $N$, where $N=254$. Based on the

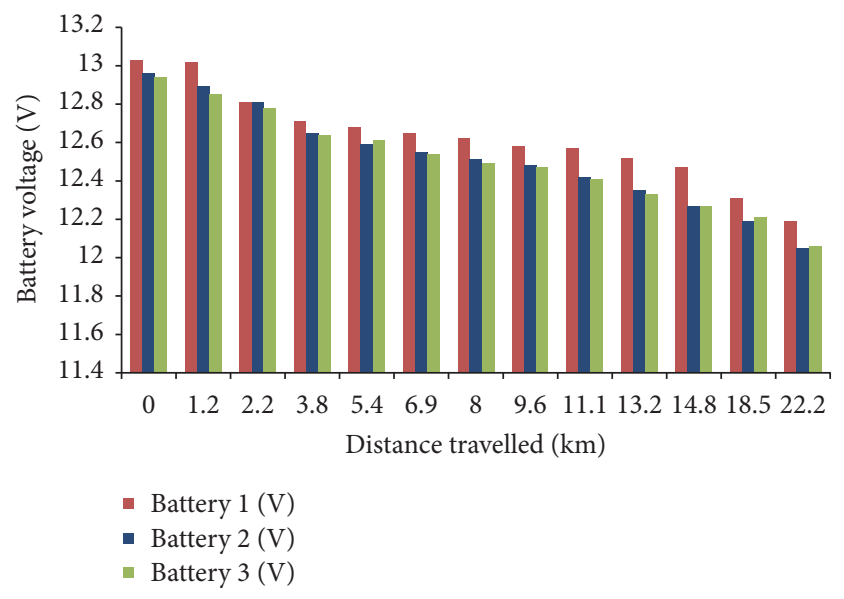

FIGURE 15: Distance covered with respect to the battery voltage discharge (using throttle).

expression as mentioned in (6), the total area under the graph is obtained by adding all the numerical values of area under each and every trapezium $\left(A_{\text {curve }}\right)$ as derived in the following expression:

$$
A_{\text {curve }}=\sum_{i=0}^{N=254} \frac{P\left(t_{i}\right)+P\left(t_{i}\right)}{2 \times\left(t_{i}-t_{j}\right)} .
$$

Applying the derived formula as provided in (7), the total amount of energy supplied by the battery to the load is $903.93 \mathrm{~kJ}$ after the completion of the field test with the battery discharged down to $50 \%$ SOC. The electric wheelchair was driven using the throttle only, and the total distance covered during the test is $22.2 \mathrm{~km}$ in 1.41 hours (5080 seconds) until the total voltage of the batteries dropped from $38.93 \mathrm{~V}$ (more than 100\% SOC) to $36.3 \mathrm{~V}$ (50\% SOC). An increase in distance travelled by the wheelchair with a decrease in the voltage of each $12 \mathrm{~V}, 12 \mathrm{Ah}$ sealed lead-acid battery is presented in Figure 15. While driving the wheelchair during the field test, the maximum speed recorded was $25.5 \mathrm{~km} / \mathrm{hr}$ and the obtained average speed for the wheelchair while running using the throttle only was $15.7 \mathrm{~km} / \mathrm{hr}$.

\subsection{Field Test Results and Analysis with the Torque Sensor} Pedal. The field test was carried out to assess and evaluate the impact of implementing the torque sensor technology on the battery performance and battery lifetime of the electrically assisted wheelchair with the torque sensor pedal. During the field test, the electric wheelchair was driven by the user continuously by the help of the torque sensor pedal only until the total voltage of the three fully charged sealed lead-acid batteries connected in series dropped from more than $100 \%$ SOC (exactly $38.93 \mathrm{~V})$ to precisely $50 \%$ SOC $(36.3 \mathrm{~V})$. The total time taken for the battery to get discharged by $50 \%$ depth of discharge (DOD) was 3 hours and 31 minutes (12660 seconds). During this period of time, the electric wheelchair covered a total distance of $42.1 \mathrm{~km}$. Figure 16 illustrates how the voltage of each $12 \mathrm{~V}$ battery discharged due to an increase in distance travelled by the wheelchair. The graph shows that 


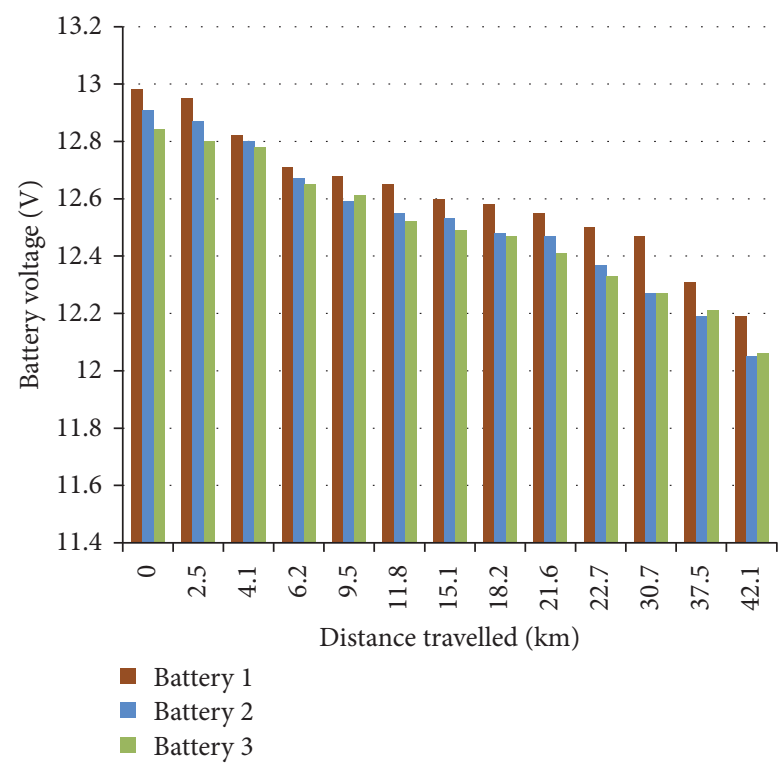

FIGURE 16: Distance completion profile depending on battery discharge using the torque sensor pedal.

the battery discharge rate with the torque sensor pedal is lower than that without the use of a torque sensor pedal, which results in almost twice the distance driven by the wheelchair user with the electrical assistance from the torque sensor pedal compared to that of the throttle. The purpose of conducting all types of field tests till the battery voltage discharges down to $50 \%$ SOC is to prevent the batteries from being overdischarged and hence to improve the lifetime of batteries per life charge.

After starting the field test, the output amplified voltage $\left(V_{1}\right)$ going to the motor controller and the torque sensor input voltage $\left(V_{\text {in }}\right)$ are measured and recorded at regular intervals of time. The graph in Figure 17 shows how both input and output voltages vary with time depending on the particular gain set before starting the field test. The minimum input torque voltage required to start the motor is $0.73 \mathrm{~V}$ and, from the graph, the maximum output voltage after amplification is found to be $3.77 \mathrm{~V}$ at a fixed gain that was chosen based on the suitability of maneuvering the electric wheelchair. The graphical trend explains that if the input torque voltage is higher than the threshold voltage, the output voltage fed to the controller unit increases with the increase in the torque sensor voltage input to the amplifier circuit. The greater the mechanical force applied to the torque sensor pedal, the higher the voltage output $\left(V_{\text {out }}\right)$ from the sensor module and the larger the current drawn by the motor [26]. Therefore, higher output torque of the motor causes the wheelchair to move faster.

While running the wheelchair with the assistance of the torque sensor pedal, batteries were discharging while supplying power to the motor and the battery voltage readings were measured and recorded every 20 seconds. While maneuvering the wheelchair on the test site by rotating the torque sensor pedal, current readings drawn from the batteries by the load were also measured and recorded every

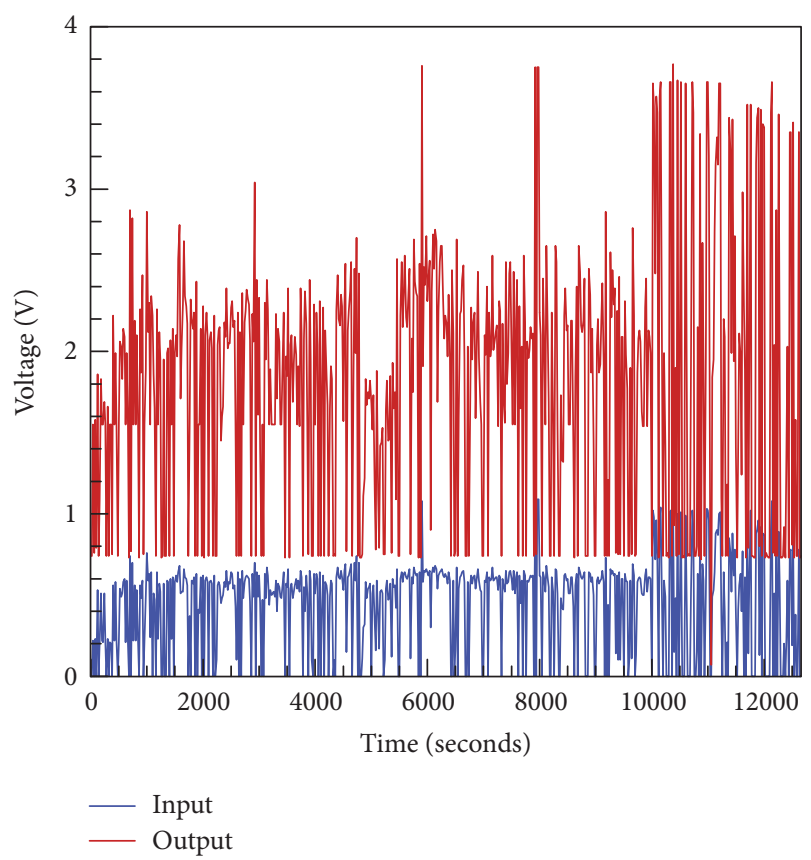

FIGURE 17: Comparison between the amplified output voltage to the motor controller and the torque sensor input voltage to the torque adjuster circuit.

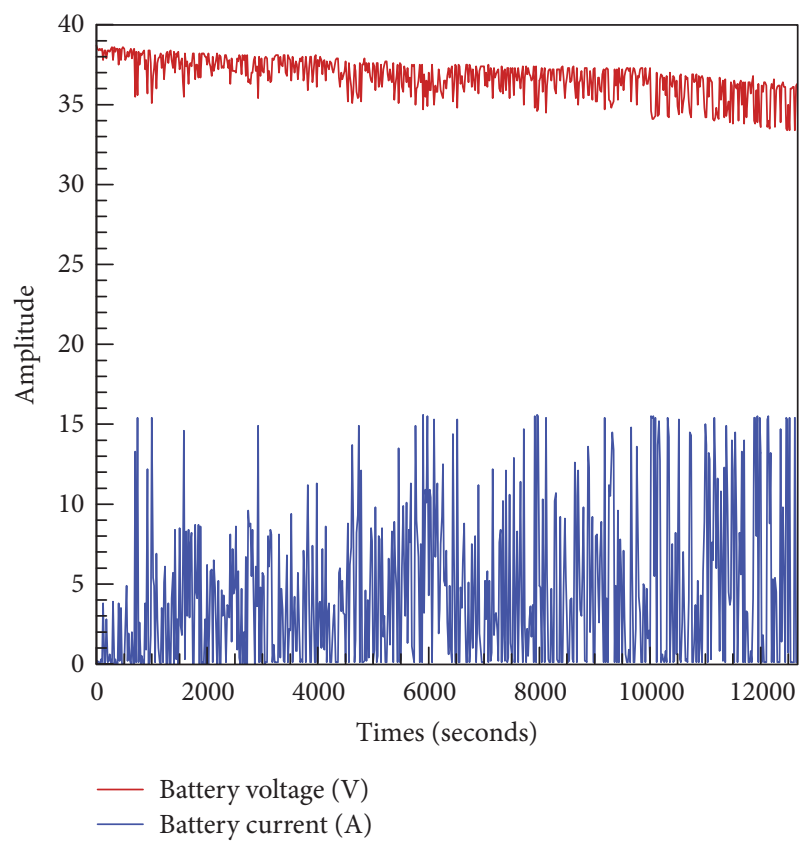

FIGURE 18: Performance of the batteries using the torque sensor pedal.

20 seconds. All the collected voltage and current readings for the battery supply profile are demonstrated in the graph as shown in Figure 18. The graphical representation in Figure 18 reveals that the average current drawn by the load is $4.4 \mathrm{~A}$ and the graph also shows that the maximum current supplied from the batteries to the load is $15.6 \mathrm{~A}$ at the exact time 


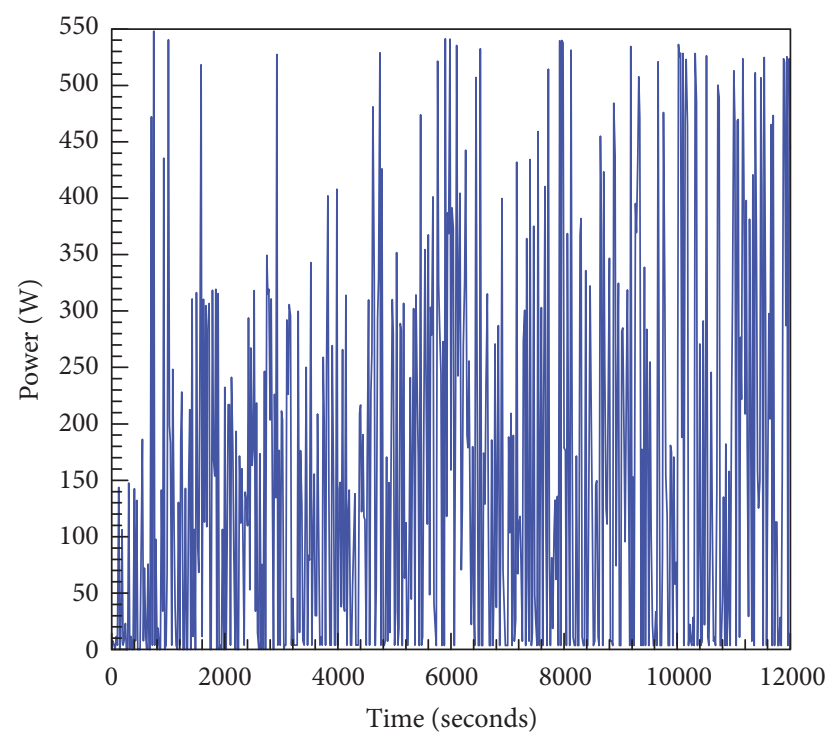

Figure 19: Power dissipated from the battery using the torque sensor pedal.

$t=7960 \mathrm{~s}$. It can be easily seen from the graph that the average battery supply voltage recorded during the running condition is $36.7 \mathrm{~V}$ and the battery voltage obtained is $34.6 \mathrm{~V}$ for the corresponding maximum load current drawn from the batteries. Comparison between the two battery supply profiles shown in Figures 13 and 18 clearly exemplifies that the maximum motor current drawn by the load and the corresponding supply voltage while driving the wheelchair using the torque sensor technology is lower than that using the throttle. Similarly, the average voltage of the battery during the discharging process was also recorded to be less in the case of conducting the test with the torque sensor pedal, which also shows that the battery usage was minimized due to the implementation of the torque sensor pedal. Figure 19 represents the amount of power dissipated from the batteries to the load at regular intervals of time. The power consumed by the electrically assisted wheelchair from the batteries is a function of time and has been calculated using (4). The maximum power dissipated to drive the hub motor at the time of operating the torque sensor pedal is $548.25 \mathrm{~W}$ at time $t=$ 548.24 s. From the graph, it has been found that the average power dissipation is $158.10 \mathrm{~W}$.

The total area under the graph of power versus time in Figure 19 is calculated using the trapezium rule as shown in the mathematical expression provided in (7). From (7), the total number of trapeziums of equal width that can be drawn between $t=0 \mathrm{~s}$ and $t=12660 \mathrm{~s}$ is denoted by $N=633$. The total calculated area gives the total amount of energy supplied by the battery to the load along with the mechanical energy supplied due to the mechanical force applied by the person to maneuver the electric wheelchair. The total energy consumption by the load during the whole test run with the assistance of the torque sensor pedal is $2004.67 \mathrm{~kJ}$. The energy supplied to the load from the battery is $903.93 \mathrm{~kJ}$ without applying the torque sensor pedal up to time

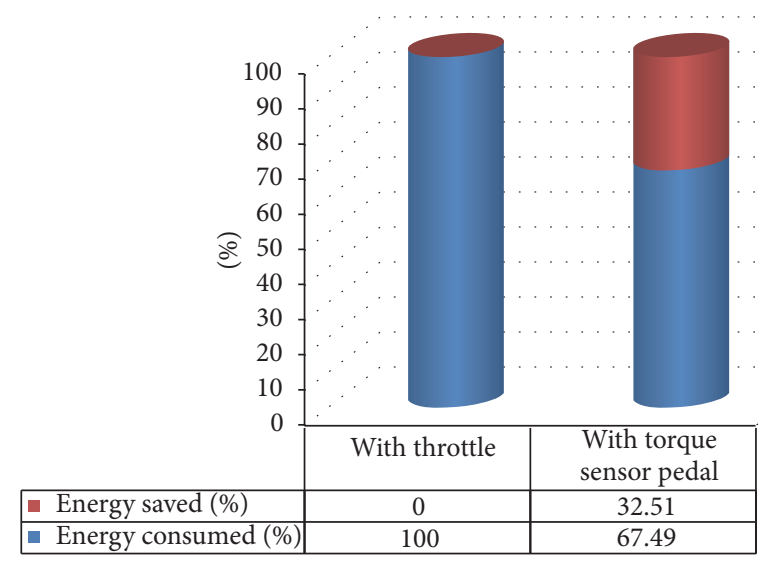

FIGURE 20: Comparison between energy saving and energy consumption with and without a torque sensor pedal.

$t=5080 \mathrm{~s}$. In contrast, the amount of energy consumed by the load obtained is $610.10 \mathrm{~kJ}$ using the torque sensor pedal for the same period of time. Hence, the percentage of energy contributed by the battery is $67.49 \%$ of the throttle controlled design and $32.51 \%$ of energy consumption by the load was contributed by the mechanical energy of the person involved during the field test. The amount of energy saved from the battery is equivalent to the energy contributed due to the mechanical force applied while driving the wheelchair using the torque sensor pedal only. The calculated amount of energy saved from the battery because of using the torque sensor pedal is $293.83 \mathrm{~kJ}$ which is shown as follows. Figure 20 presents the impact of introducing the torque sensor pedal on the battery performance in terms of the percentage of energy saved and energy consumed by the battery. Figure 20 provides statistical data which clarify the energy saving from the battery for implementing the torque sensor pedal. Energy saved from the battery = energy supplied using throttle energy supplied using the torque sensor pedal $=903.93-$ $610.10 \mathrm{~kJ}=293.83 \mathrm{~kJ}$.

4.4. Load Test Results and Analysis with the Torque Sensor Pedal. The field test was performed by carrying the extra load of $20 \mathrm{~kg}$ on the wheelchair along with the $60 \mathrm{~kg}$ test subject, who drove the electric wheelchair using the torque sensor pedal. The objective of conducting the field test with a total weight of $80 \mathrm{~kg}$ is to find out the impact of varying the weight on the battery performance of the electric wheelchair. The test was conducted until the battery discharged down to $70 \%$ SOC which is $37.1 \mathrm{~V}$. The battery discharge profile as shown in Figure 21 shows recorded battery voltage readings and corresponding current readings drawn from the battery at regular intervals of time. The graph in Figure 21 shows that the total time elapsed is 1600 seconds for discharging the battery from $100 \%$ SOC $(38.2 \mathrm{~V})$ to $70 \%$ SOC. In some cases, the current drawn from the battery was recorded as $0 \mathrm{~A}$ when the wheelchair was stationary and the motor current increased rapidly to a high value in some situations when the starting torque of the motor was high at the time of operating the wheelchair. It can be seen from the data in 


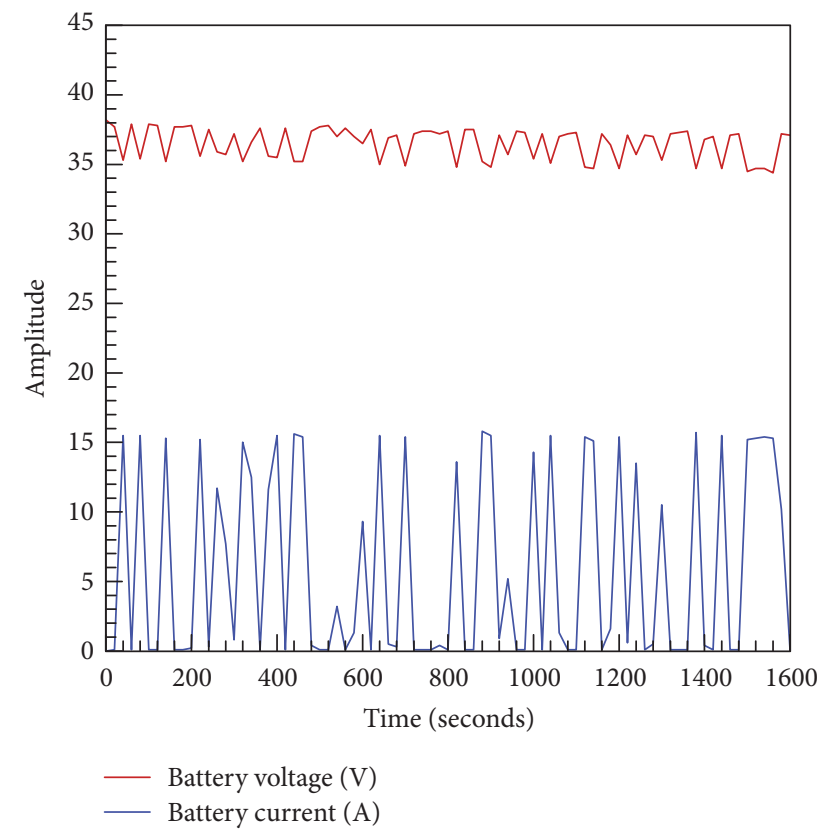

Figure 21: Battery discharge cycle using the torque sensor pedal.

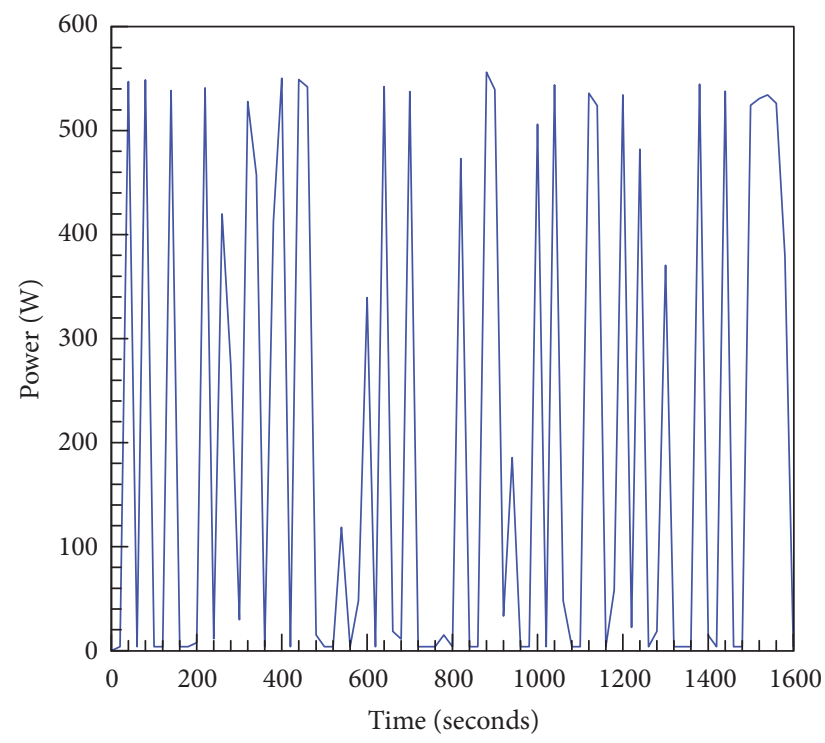

FIGURE 22: Power dissipation cycle of the battery for $80 \mathrm{~kg}$ load.

Figure 21 that the average current drawn from the battery is 5.9 $\mathrm{A}$ and the maximum current drawn by the load is $15.8 \mathrm{~A}$ which was recorded when the starting torque of the motor was maximum. Power $P(t)$ supplied by the battery at time $t$ seconds is a function of time and has been calculated using (4). The graph of power dissipation from the battery to the load versus time is displayed in Figure 22. The graphical data reveal that the average power dissipation is $206.78 \mathrm{~W}$ and the maximum instantaneous calculated power consumption from the battery bank is $556.16 \mathrm{~W}$ at time $t=880$ seconds. The total amount of energy consumed from the battery bank is equal to the total area under the graph of power consumed

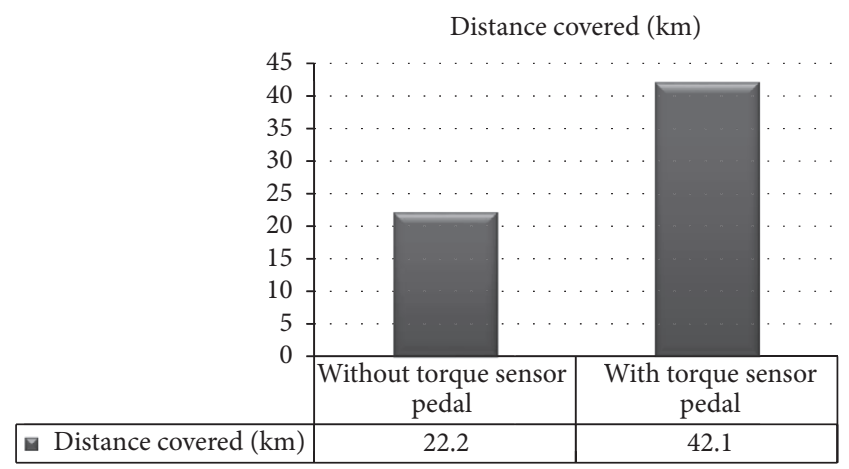

FIGURE 23: Comparing the distance coverage up to $50 \%$ SOC of the battery.

against time as shown in Figure 22. The total area under the power dissipation curve has been calculated by drawing a trapezium of equal width within the total time of $t=1600$ seconds and adding up the different values of each trapezium using the mathematical expression as mentioned in (7), where the total number of trapeziums that can be drawn is $N=80$, with uniform width of $\left(t_{i}-t_{j}\right)=20$. The area of each trapezium differs due to different values of power dissipation $(W)$ at a different time $(t)$. The total amount of energy consumed by the load is equivalent to the energy supplied from the battery along with the mechanical energy supplied by the mechanical force exerted by the person to maneuver the electric wheelchair. The total amount of energy consumed by the load is $334.94 \mathrm{~kJ}$ with the torque sensor pedal till the completion of the field test until $t=1600 \mathrm{~s}$. However, the energy consumed by the load using the throttle with the battery discharged down to $70 \%$ SOC is $652.78 \mathrm{~kJ}$, which elucidates that the battery usage using the torque sensor pedal with extra weight $(80 \mathrm{~kg})$ is less compared to that using the throttle having the weight of $60 \mathrm{~kg}$.

4.5. A Comparative Study of Battery Performance with and without a Torque Sensor Pedal. The test results obtained with the throttle and without the throttle (use of torque sensor pedal) can be compared to determine the difference in distance covered by the electric wheelchair and validate the improvement in the battery lifetime and battery performance. One of the parameters that have been kept constant during conducting both field tests is the weight of the test subject $(60 \mathrm{~kg})$, who drove the electric wheelchair. Applying the torque sensor technology on the electrically assisted wheelchair increases the distance coverage significantly and, consequently, it took a longer time to discharge all the three batteries from $100 \%$ SOC to $50 \%$ SOC. The differences in the distance covered and the time required to complete the individual field tests using the torque sensor pedal and using the throttle are presented in Figures 23 and 24, respectively. Moreover, at the end of the field tests, the total energy consumption using the torque sensor pedal was $2004.67 \mathrm{~kJ}$ in 12660 seconds and the energy consumption by the load with the throttle only was $903.93 \mathrm{~kJ}$ within 5080 seconds. However, the total energy consumption using the torque sensor pedal 


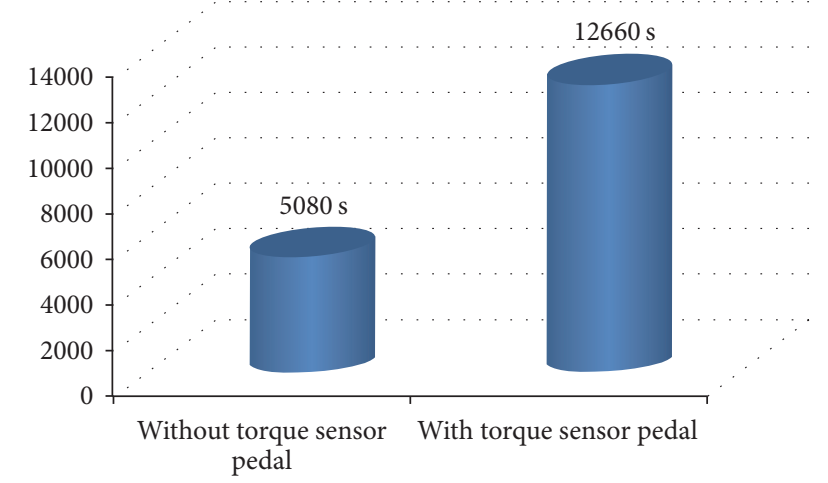

FIgURE 24: Comparisons between the time durations of two different field tests.

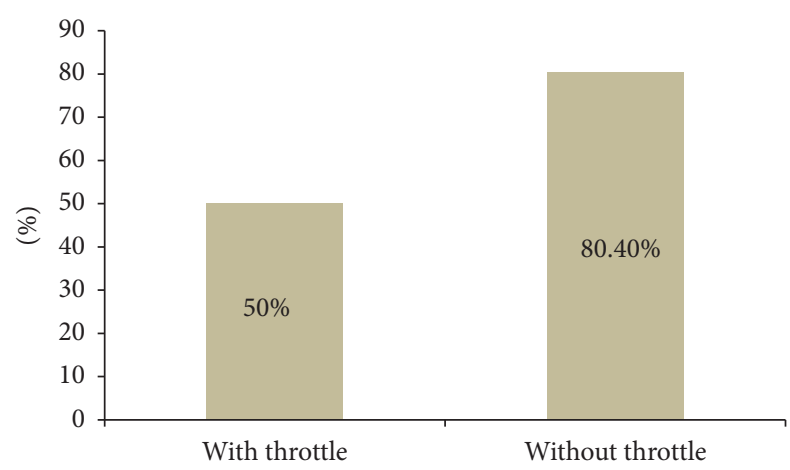

FIGURE 25: Battery SOC remaining with and without the use of throttle.

for 5080 seconds is $293.83 \mathrm{~kJ}$ lower than the energy consumed by the load while running the wheelchair without the support from the torque sensor pedal. By contrasting the energy consumption during both tests for the same time period of $t=5080 \mathrm{~s}$, the state of charge (SOC) of the batteries can be found in order to determine the battery usage as shown in Figure 25. The statistical data that have been found highlight that the battery SOC is $80.4 \%(37.7 \mathrm{~V})$ and that only $19.60 \%$ of the available battery energy was used with the torque sensor pedal until the time $t=5080 \mathrm{~s}$. On the other hand, the SOC of the battery remaining is $50 \%(36.3 \mathrm{~V})$; that is, $50 \%$ of the battery's energy was consumed using the throttle only (without the use of the torque sensor pedal) after conducting the field test for the same period of time $(t=$ 5080 s). Therefore, the results obtained clarify that the battery usage is minimized due to the implementation of torque sensor technology on the electric wheelchair. Moreover, the lower energy consumption of the batteries or attaining lower DOD using the torque sensor pedal means the battery life is expected to be more than the conventional way of discharging the batteries using the throttle. Consequently, the battery lifetime can also be improved by the use of a torque sensor pedal instead of using the throttle, allowing greater distance coverage and longer time required to discharge the battery with a lower rate of discharge compared to that using the throttle.

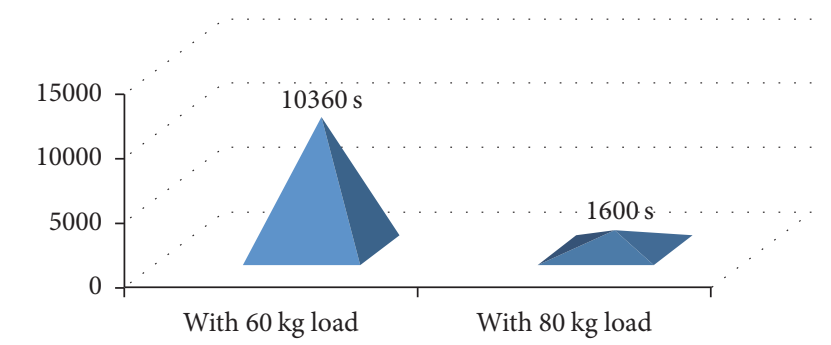

Figure 26: Time elapsed with different loads with batteries discharged down to $70 \%$ SOC.

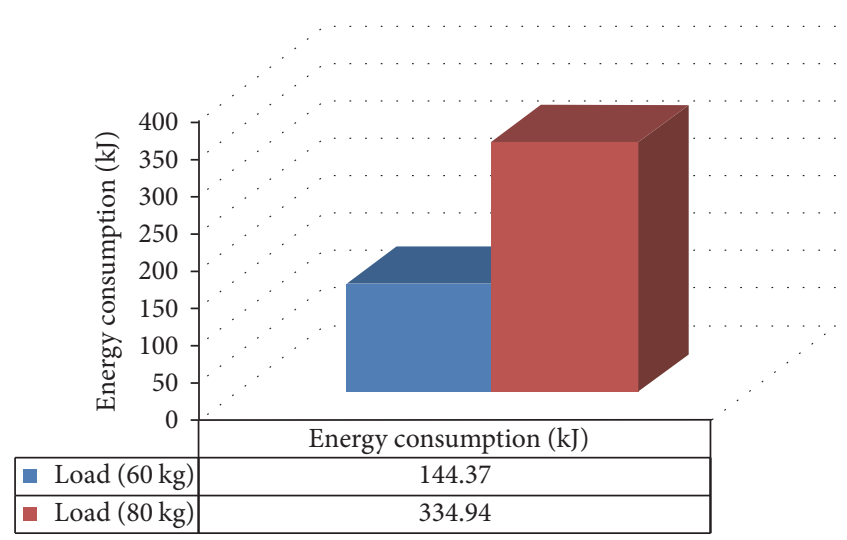

FIGURE 27: Comparison between the energy consumption levels with different loads for the same time period.

4.6. A Comparative Study of Battery Performance with the Torque Sensor Pedal Based on the Different Weight of the Load. Field tests were conducted using $60 \mathrm{~kg}$ and $80 \mathrm{~kg}$ load on the electric wheelchair using the torque sensor pedal. The test results obtained, which are revealed in Figure 26, depict that the time required to operate the electric wheelchair having an additional load of $20 \mathrm{~kg}$ is 1600 seconds with the battery discharged down to $70 \%$ SOC. However, the time required to discharge the batteries using the torque sensor pedal for $60 \mathrm{~kg}$ load test is around 6 times greater with the battery voltage discharged down to $70 \%$ SOC. The total amount of energy consumed by the load of $80 \mathrm{~kg}$ is $334.94 \mathrm{~kJ}$ in 1600 seconds, whereas the energy consumed by the $60 \mathrm{~kg}$ load at the same time is $144.37 \mathrm{~kJ}$ as presented in Figure 27. After conducting the field test for 1600 seconds with $60 \mathrm{~kg}$ load, the SOC of the battery bank remained $100 \%(38.2 \mathrm{~V})$. But, with an increase of an additional $20 \mathrm{~kg}$ load, the SOC of the battery bank recorded was $70 \%(37.1 \mathrm{~V})$ after 1600 seconds as shown in Figure 28. According to the findings of the test data, batteries consumed more energy due to the increase in load and wheelchairs travelled for a shorter time because of the higher rate of discharge of the battery. Hence, the amount of energy consumed by the battery depends on the weight of the load which is one of the important factors that determines the performance of the batteries at the time of providing power to the hub motor of the electric wheelchair with the help of the torque sensor pedal. 


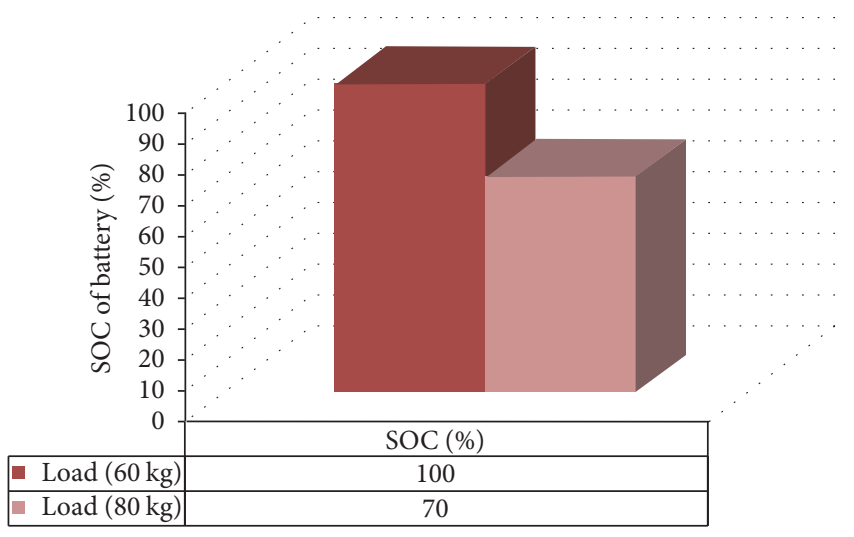

FIGURE 28: SOC of the battery bank with different loads using a torque sensor pedal for the same time period.

4.7. Comparison between the Proposed Torque Sensor Technologies for the Developed Electric Wheelchair with That of Existing Electric Tricycle Battery-Powered Technology. The application of battery-powered technology to drive the electric motor that is incorporated with a four-wheeler electric wheelchair for replacing manually driven wheelchairs and to ease manual human effort has gained worldwide popularity among the disabled people in developed countries. Electric tricycles $[8,27]$ have been introduced by Rio Mobility, which allow minimizing the human effort because this type of wheelchair relies solely on power from the battery to drive the motor that is connected with the front wheel. Even though it eliminates the manual effort, the existing technology had the following disadvantages for this type of electric tricycles, which has been overcome by the implementation of the proposed torque sensor pedal technology for the electric wheelchair, and they are mentioned below.

(1) Since the electric tricycle can only be driven by solely taking power from a low capacity (each $6.6 \mathrm{Ah}$ ) Liion battery to run a high-powered $350 \mathrm{~W}$ brushless and geared hub motor, battery longevity and lifetime are reduced and lower due to its prolonged usage. On the other hand, the integration of a torque sensor pedal in the developed electrically assisted triwheeler wheelchair allows driving the wheelchair by applying the torque sensor pedal technology which in turn increases the high capacity (each $12 \mathrm{Ah}$ ) battery longevity by reducing the power consumption from the batteries by the low-powered $250 \mathrm{~W}$ hub motor.

(2) The total distance covered by the electric powered tricycle with the electrical assist from low capacity (each battery $6.6 \mathrm{Ah}$ ) is smaller $(24 \mathrm{~km})$ than the total distance covered $(42.1 \mathrm{~km})$ by the developed electric triwheeler for the wheelchair with the torque sensor pedal technology having a high capacity (each $12 \mathrm{Ah}$ ) sealed lead-acid battery.

(3) The electric powered tricycle is expensive (\$1950) [27], whereas the developed electric triwheeler having the proposed torque sensor technology is affordable
(\$625) and cost-effective as the proposed torque sensor pedal technology is cheaper to implement on the electric triwheeler wheelchair, along with affordable batteries used as a source of power and cheaper hub motor.

(4) It takes 4 hours to discharge the Li-ion batteries completely, which means that the total continuous runtime for the electric tricycle is 4 hours. Due to the application of the proposed torque sensor technology for the developed electric wheelchair, the total time it takes to discharge fully charged sealed lead-acid batteries up to only $50 \%$ SOC is 3 hours and 31 minutes. Therefore, with only $50 \%$ battery discharge, the total distance covered by the developed electric wheelchair integrated with the proposed torque sensor technology is almost equal to that of the total mileage covered by the electric tricycle.

Even though the implementation of the proposed torque sensor pedal technology has addressed the limitations of the traditional available electric powered triwheeler wheelchairs, there are some existing cons in this proposed torque sensor technology based developed electric wheelchair. The drawbacks of the proposed technology compared to that of existing battery-powered technology on electric tricycles are mentioned below [27].

(1) Disc brakes are not available, and only V-brake systems work with the proposed torque sensor technology implemented in the developed electric wheelchair, whereas both V-brake and disc brake systems are available in the electric tricycle that works with the existing battery-powered technology.

(2) The application of a reverse gear system along with a reverse switch is not available in the proposed torque sensor technology that is applied for the developed electric wheelchair; only forward movement can be achieved. However, the available traditional electric tricycle $[8,27]$ can be driven both in reverse and in forward directions through the application of the existing technology that consists of using both forward and reverse thumb throttles.

\section{Conclusion}

Traditional electric triwheeler vehicles, especially wheelchairs, exclude the manual effort of users completely by the use of throttle for mobility, which causes in the SOC of the batteries to decline rapidly and in turn reduces the battery lifetime. Considering the importance of improving the battery performance and its longevity, we have designed and developed an electric wheelchair and implemented torque sensor technology to provide an alternative solution for the improvement of battery performance and the battery lifetime. Development of the new technology in electrically assisted wheelchairs helps physically disabled people with better outdoor and indoor mobility by allowing the application of minimum human effort to maneuver the wheelchair using the torque sensor pedal. Field test results 
and analysis show longer distance coverage due to the usage of a torque sensor pedal compared to that without using the torque sensor pedal. Adopting the torque sensor technology validates the notion that the obtained results improve the battery performance, minimizing the energy consumption from batteries by the load compared to that using the throttle controlled design and allowing discharge of the batteries to get reduced for the same period of runtime, which leads to the increase of the battery life per charge. Moreover, the usage of this electric wheelchair by disabled people is also feasible in rural off-grid areas by the development and implementation of a dedicated solar charger kit [22] that will be incorporated with the electric wheelchair. The implementation of the dedicated solar charger kit in the future will enable the user to have backup batteries that will be charged completely by solar energy using photovoltaic panels, and these charged batteries can be swapped by the discharged batteries of the wheelchair. Thus, by adopting this renewable energy technology, disable people living in those areas, where there is no electricity available from the grid, can use this electric wheelchair without worrying about the battery charging issue as batteries can be easily charged by using the dedicated solar charger kit (SCK).

\section{Conflicts of Interest}

The authors declare that they have no conflicts of interest regarding the publication of this manuscript.

\section{Acknowledgments}

The authors would like to thank the IEEE SIGHT USA section for funding and supporting, with kind cooperation, this research work. The authors would also like to thank the Centre for Rehabilitation of the Paralyzed (CRP) for allowing them to use their premises for testing the prototype and their valuable suggestions regarding improving the prototype.

\section{References}

[1] "Disability prevention and rehabilitation, WHO Expert Committee report," http://www.who.int/disabilities/publications/ care/en/index.html.

[2] "Convention on the rights of persons with disabilities: some facts about persons with disabilities," http://www.un.org/ disabilities/convention/facts.

[3] A. Elwan, "Poverty and disability: a survey of the literature," Social Protection Research, pp. 5-6, 1999, http://documents .worldbank.org/curated/en/488521468764667300/pdf/multipage.pdf.

[4] "Facts on disability in the world of work (2007)," http://www.ilo .org/wcmsp5/groups/public/_dgreports/-dcomm/documents/ publication/wcms_087707.pdf.

[5] A. Abdi and etal., Reaching The Marginalized. EFA Global Monitoring Report, United Nations Educational Scientific And Cultural Organization, vol. 12, Oxford University Press, France, 2010, http://unesdoc.unesco.org/images/0018/001866/186606E .pdf.
[6] "Rio mobility dragonfly lightweight handcycle for manual wheelchair," http://www.broadenedhorizons.com/dragonflyhandcycle.

[7] R. R. Cooper and etal., "Heavy handed: repetitive strain injury among manual wheelchair users," Teamreha. Report, vol. 35, 1998.

[8] "Firefly electric hand cycle," https://riomobility.com/.

[9] J. Mullen, Electric Wheelchairs-Helping Physically Challenged People, Personal Training.

[10] R. Kandasemy, S. Raut, D. Verma, and G. There, "Design of solar tricycle for handicapped person," Journal of Mechanical and Civil Engineering, vol. 25, no. 2, pp. 11-24, 2013.

[11] S. Chowdhury, R. Rahman, and A. Azad, "The solar assisted rickshaw van: a complete off-grid solution," IEEE Transportation Electrification newsletter, http://tec.ieee.org/ newsletter/january-february-2015/the-solar-assisted-rickshawvan-a-complete-off-grid-solution.

[12] M. Akamatsu, P. Green, and K. Bengler, "Automotive technology and human factors research: past, present, and future," International Journal of Vehicular Technology, vol. 2013, Article ID 526180, pp. 1-27, 2013.

[13] A. Panday and H. O. Bansal, "A review of optimal energy management strategies for hybrid electric vehicle," International Journal of Vehicular Technology, vol. 2014, Article ID 160510, pp. 1-9, 2014.

[14] C. Shen, P. Shan, and T. Gao, "A comprehensive overview of hybrid electric vehicles," International Journal of Vehicular Technology, vol. 2011, Article ID 571683, pp. 1-7, 2011.

[15] M. A. Roscher, R. Michel, and W. Leidholdt, "Improving energy conversion efficiency by means of power splitting in dual drive train EV applications," International Journal of Vehicular Technology, vol. 2013, Article ID 398361, pp. 1-5, 2013.

[16] G. Srinivasa Rao, G. Kesava Rao, and S. S. N. Raju, "An innovative approach to battery management and propulsion system of electric/hybrid vehicle," International Journal of Electric and Hybrid Vehicles, vol. 6, no. 1, pp. 1-3, 2014.

[17] M. Vajedi, M. Chehrehsaz, and N. L. Azad, "Intelligent power management of plug-in hybrid electric vehicles, part I: Realtime optimum SOC trajectory builder," International Journal of Electric and Hybrid Vehicles, vol. 6, no. 1, pp. 46-67, 2014.

[18] J. Gonder and T. Markel, "Energy management strategies for plug-in hybrid electric vehicles," SAE Technical Papers, vol. 1, 2007.

[19] S. J. Chowdhury, R. Rahman, and A. Azad, "Power conversion for environment friendly electrically assisted rickshaw using photovoltaic technology in Bangladesh," in Proceeding of IEEE Transportation Electrification Conference and Expo (ITEC '15), Detroit, USA, 2015.

[20] "Victory Sincerity Technology Co. Ltd" http://www.jcebike com/Product-68.html.

[21] "Rotary torque sensor," https://www.transducertechniques .com/torque-sensor.aspx.

[22] A. Azad, "Electrically assisted torque sensor based wheelchair with dedicated solar charge kit," IEEE Transportation Electrification Newsletter, 2016, http://tec.ieee.org/newsletter/ march-2016/electrically-assisted-torquesensor-based-wheelchair-with-dedicated-solar-charger-kit.

[23] F. R. Khan, A. T. Aurony, A. Rahman, F. Munira, N. Halim, and A. Azad, "Torque sensor based electrically assisted hybrid rickshaw-van with PV assistance and solar battery charging station," in Proceedings of the 3rd International Conference 
on Advances in Electrical Engineering, (ICAEE '15), Dhaka, Bangladesh, December 2015.

[24] "Torque sensor operation manual v4.0; Suzhou Victory Sincerity Co., Ltd," http://jcebike.en.china.cn/selling-leads/detail, 1136954561, Torque-Sensor.html.

[25] R. M. Huq and etal., "Development of torque sensor based electrically assisted hybrid rickshaw," BRAC University, 2012, http://dspace.bracu.ac.bd/handle/10361/2122.

[26] T. Faraz and A. Azad, "Solar battery charging station and torque sensor based electrically assisted tricycle," in Proceedings of the 2nd IEEE Global Humanitarian Technology Conference, (GHTC '12), pp. 18-22, EEE, Seattle, WA, USA, October 2012.

[27] "Firefly attachable full power handcycle," https://riomobility .com/firefly/. 


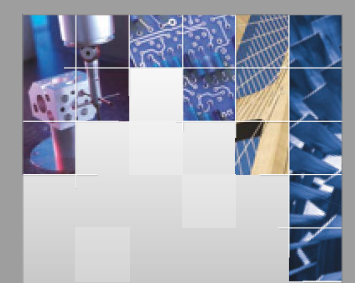

\section{Enfincering}
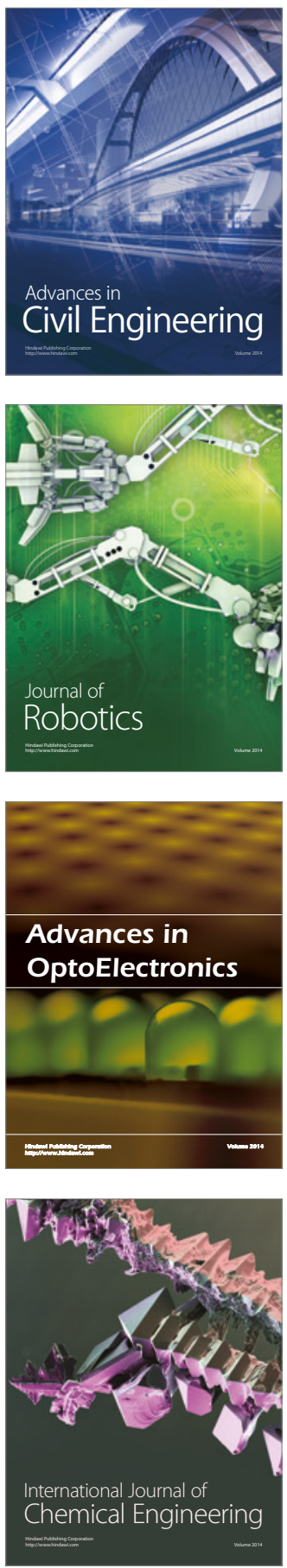

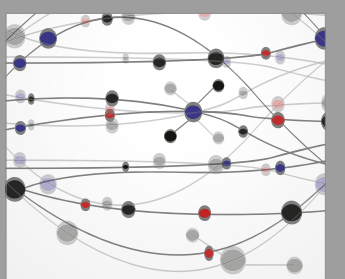

The Scientific World Journal

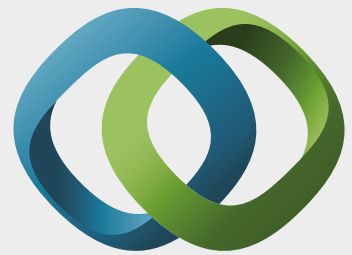

\section{Hindawi}

Submit your manuscripts at

https://www.hindawi.com
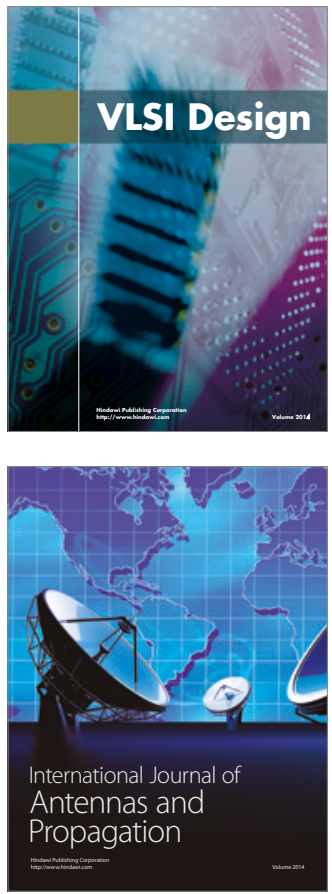

\section{Rotating}

Machinery
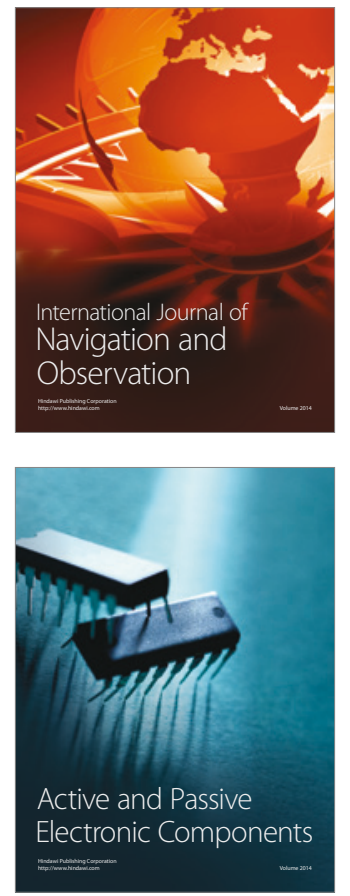
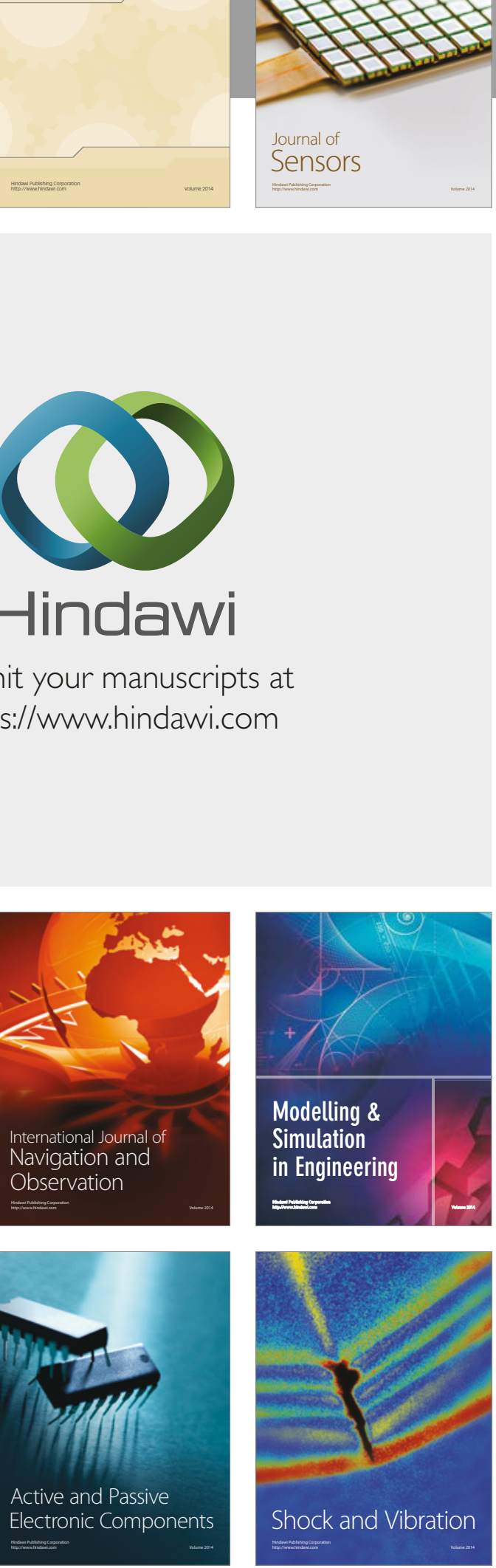
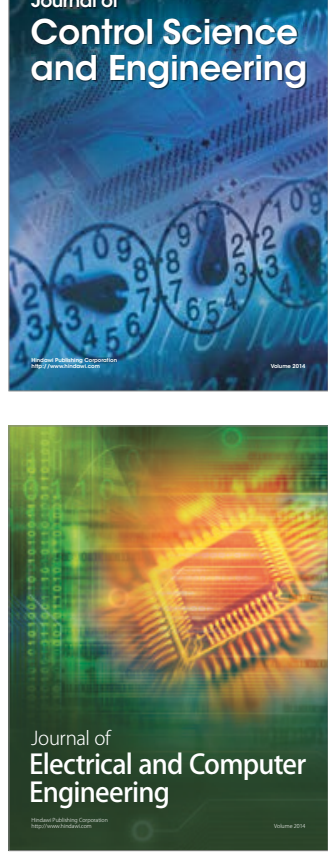

Distributed

Journal of

Control Science

and Engineering
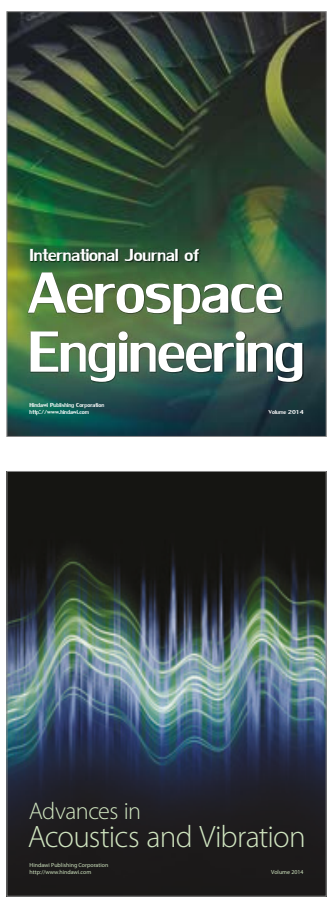

Sensor Networks 